Manuscript Number: AB-17-1735R1

Title: Copper containing mesoporous bioactive glass promotes angiogenesis in an in vivo zebrafish model

Article Type: Full length article

Keywords: Angiogenesis; Zebrafish; Mesoporous bioactive glass (MBG) ; Copper (Cu); Subintestinal vessels (SIVs).

Corresponding Author: Dr. Aránzazu Díaz Cuenca, Ph. D.

Corresponding Author's Institution: Spanish National Research Council ( CSIC)

First Author: Lilian B Romero-Sánchez

Order of Authors: Lilian B Romero-Sánchez; Manuel Marí-Beffa; Paloma Carrillo; Miguel Ángel Medina; Aránzazu Díaz Cuenca, Ph. D.

Abstract: The biological responses of osteogenesis and angiogenesis to the ionic degradation products from bioactive glasses (BGs) are being intensively investigated. The promotion of angiogenesis by copper (Cu) has been known for more than three decades, and this element can be incorporated to delivery carriers, such as BGs. In this work, Cucontaining mesoporous bioactive glass (MBG) in the SiO2-CaO-P2O5 compositional system was prepared incorporating 5\% mol Cu (MBG-5Cu) by replacing the corresponding amount of Ca. The biological effects of MBG biodegradation ionic products are evaluated on a well-known endothelial cell line, the bovine aorta endothelial cells (BAEC), in an in vivo zebrafish (Danio rerio) embryo assay and their effects compared. The results suggest that both $\mathrm{MBG}$ ( $\mathrm{Cu}$ free) and $\mathrm{MBG}-5 \mathrm{Cu}$ materials biodegradation ionic products promote angiogenesis. In vitro cell cultures show that the ionic dissolution products of the $\mathrm{MBG}$ and $\mathrm{MBG}-5 \mathrm{Cu}$ materials are not toxic but promote BAEC viability and migration. In addition, the in vivo assay indicates that MBG ( $\mathrm{Cu}$ free) material increases vessel number and thickness of the subintestinal venous plexus (SIVP) in 120 hours post-fertilization zebrafish specimens in experiments of both material exposition and microinjection. In vivo results also reveal that $\mathrm{MBG}-5 \mathrm{Cu}$ material possesses a stronger angiogenesis stimulatory effect when compared with MBG and control groups.

This is the preprint version of our manuscript, corresponding to the article that has been published in final form at ACTA BIOMATERIALIA with DOI: $10.1016 / j . a c t b i o .2017 .12 .032$ 
Mesoporous bioactive glasses (MBGs) with high specific surface area, well-ordered pores, large pore volumes and controllable amount of ions are interesting to develop controlled drug delivery systems for bone tissue regeneration. Copper $(\mathrm{Cu})$ incorporation to the basic $\mathrm{SiO}_{2}-\mathrm{CaO}-\mathrm{P}_{2} \mathrm{O}_{5}$ composition has attracted high interest due to its multifunctional biological properties. Promotion of angiogenesis is one of these properties, which can be integrated to the biomaterial with lower cost and higher stability when compared with growth factors.

This work reports the synthesis and characterization of $\mathrm{Cu}$-containing $\mathrm{MBG}$ evaluating its angiogenic properties in the subintestinal vessel zebrafish assay. This transgenic in vivo assay is merging as an alternative model providing short-time consuming protocols and facilities during pro-angiogenic drug screenings. The report shows that the ionic products of this MBG material delivered to the zebrafish incubation media significantly enhance angiogenesis in comparison with control groups. Besides, results indicate $\mathrm{Cu}$ ions may exhibit a synergic effect with $\mathrm{Si}, \mathrm{Ca}$, and $\mathrm{P}$ ions in angiogenesis stimulation both in vitro and in vivo. To our knowledge, this is the first time that zebrafish in vivo assays are used to evaluate angiogenic activity of ionic dissolution products from MBG materials. 


\section{Copper containing mesoporous bioactive glass promotes angiogenesis in an in vivo zebrafish model}

\section{Lilian B. Romero-Sánchez ${ }^{\mathrm{a}}$, Manuel Marí-Beffa ${ }^{\mathrm{b}, \mathrm{c}}$, Paloma Carrillo ${ }^{\mathrm{d}}$,} Miguel Ángel Medina ${ }^{\mathrm{d}, \mathrm{e}}$, Aránzazu Díaz-Cuenca ${ }^{\mathrm{a}, \mathrm{c}, *}$

${ }^{\text {a }}$ Materials Science Institute of Seville (ICMS), Joint CSIC-University of Seville Center, C/ Américo Vespucio 49, Isla de la Cartuja, 41092 Seville, Spain

${ }^{\mathrm{b}}$ Department of Cell Biology, Genetics and Physiology, Faculty of Science, University of Malaga, 29071 Malaga, Spain

${ }^{\mathrm{c}}$ Networking Research Center on Bioengineering, Biomaterials and Nanomedicine (CIBERBBN), Spain

${ }^{\mathrm{d}}$ Department of Molecular Biology and Biochemistry, Faculty of Science, University of Malaga, 29071 Malaga, Spain

${ }^{\mathrm{e}}$ Networking Research Center on Rare Diseases (CIBER-ER), Spain

* Corresponding author: Aránzazu Díaz-Cuenca

Tel. $+34954489542 ;$ Fax +34954460165

E-mail address: aranzazu@icmse.csic.es 


\section{Abstract}

The biological responses of osteogenesis and angiogenesis to the ionic degradation products from bioactive glasses (BGs) are being intensively investigated. The promotion of angiogenesis by copper $(\mathrm{Cu})$ has been known for more than three decades, and this element can be incorporated to delivery carriers, such as BGs. In this work, $\mathrm{Cu}$-containing mesoporous bioactive glass (MBG) in the $\mathrm{SiO}_{2}-\mathrm{CaO}-\mathrm{P}_{2} \mathrm{O}_{5}$ compositional system was prepared incorporating $5 \%$ mol $\mathrm{Cu}(\mathrm{MBG}-5 \mathrm{Cu})$ by replacing the corresponding amount of $\mathrm{Ca}$. The biological effects of MBG biodegradation ionic products are evaluated on a well-known endothelial cell line, the bovine aorta endothelial cells (BAEC), in an in vivo zebrafish (Danio rerio) embryo assay and their effects compared. The results suggest that both $\mathrm{MBG}(\mathrm{Cu}$ free) and $\mathrm{MBG}-5 \mathrm{Cu}$ materials biodegradation ionic products promote angiogenesis. In vitro cell cultures show that the ionic dissolution products of the MBG and MBG-5Cu materials are not toxic but promote BAEC viability and migration. In addition, the in vivo assay indicates that $\mathrm{MBG}(\mathrm{Cu}$ free) material increases vessel number and thickness of the subintestinal venous plexus (SIVP) in 120 hours post-fertilization zebrafish specimens in experiments of both material exposition and microinjection. In vivo results also reveal that $\mathrm{MBG}-5 \mathrm{Cu}$ material possesses a stronger angiogenesis stimulatory effect when compared with MBG and control groups.

Keywords: Angiogenesis, Zebrafish, Mesoporous bioactive glass (MBG), Copper $(\mathrm{Cu})$, Subintestinal vessels (SIVs).

\section{Introduction}

Studies on potential regenerative therapies are evaluating the use of growth factor-free biomaterials to induce de novo tissue formation and growth to repair wounded tissues. Examples are found to promote angiogenesis (to induce vascular sprouting and growth) or osteogenesis to repair long bone defects [1-3]. It has been demonstrated that bioactive glasses (BGs) ionic biodegradation products (e.g. $\mathrm{Si}, \mathrm{Ca}, \mathrm{P}$ and $\mathrm{Na}$ ) are able not only to induce and 
stimulate the expression of genes related to osteoblastic differentiation and bone formation $[4,5]$ but to stimulate angiogenesis in vitro and in vivo [6,7]. Some authors suggest that biomaterials that produce $\mathrm{Si}$ degradation products have stimulatory effects on upregulation of angiogenic growth factors. In vitro assays with endothelial cells have shown that 45S5® Bioglass stimulates vascular endothelial growth factor (VEGF) and basic fibroblast growth factor (bFGF) secretion [6]. Studies in vivo using mice indicate that BG-coated collagen scaffolds and systems prepared using BGs also induce endothelial cell proliferation and neovascularization by augmenting VEGF and bFGF concentrations [7]. In addition, other biomaterials also based on silica have been found to stimulate VEGF expression $[2,8]$.

Copper $(\mathrm{Cu})$ promotion of angiogenesis is known for more than three decades [9] and it has attracted intensive attention due to their low cost and high stability as compared with growth factors [10]. It has been confirmed that $\mathrm{Cu}$ is able to promote angiogenesis by stabilizing the expression of hypoxia-inducible factor (HIF-1 $\alpha$ ) and secretion of VEGF of bone marrow stromal cells, thus artificially mimicking hypoxia, which plays an important role in recruitment and differentiation of cells and in blood vessel formation [11-13]. Besides, $\mathrm{Cu}$ ions may also be involved in extracellular matrix (ECM) degradation and remodeling [14].

Mesoporous bioactive glasses (MBGs) are advanced BGs with nanostructured porosity, high specific surface area, very high bioactivity and drug delivery capacity [15]. Besides its textural properties and potentiality for 3D-scaffold processing [16,17], pro-angiogenic elements, such as $\mathrm{Cu}$, can be incorporated to this system providing new therapeutic properties to the biomaterial. $\mathrm{Cu}$ has been recently added to this system to enhance angiogenic activity $[18,19]$. Wu and col. [18] processed MBG-Cu (Cu content 1, 2 and 5\% mol) 3D scaffolds by the replica technique. MBG-Cu scaffolds showed a potent anti-bacterial effect and induced bone-related (alkaline phosphatase, ALP; osteopontin, OPN; and osteocalcin, OCN) and angiogenic-related (HIF-1 $\alpha$ and VEGF) gene expression in human bone marrow stromal cells (hBMSC). 
Previous studies have analyzed the process of angiogenesis primarily using in vitro cell culture experiments. In vivo models to study angiogenesis have been introduced in the field of tissue engineering, including the chorioallantoic membrane (CAM), mouse corneal micropocket, and rodent model assay [20]. These assays have been used to evaluate the angiogenic effects of bioceramics and bioactive silicate glasses and their biodegradation products [7].

Recently, zebrafish has emerged as an alternative in vivo model to study angiogenesis [21]. Zebrafish (Danio rerio) provides a number of powerful advantages as a model of study due to its rapid external embryonic development, small size, optical transparency, and high number of offspring [22]. Furthermore, zebrafish share a high genetic similarity to humans as approximately $70 \%$ of all human disease genes have functional homologs in zebrafish [23]. A tissue-specific germ line-induced transgenic line promotes Enhanced Green Fluorescence Protein (EGFP) expression in all endothelial cells under the Friend leukemia integration-1 (Fli1) promoter, a well-known endothelium marker in mice [24]. The $T g(F l i-1: E G F P)^{y 1}$ transgenic zebrafish strain is one of several lines that also shows EGFP expression in endothelial cells during early embryonic vascular development [25]. This is an ideal system to obtain images of both vascular development and adult blood vessels in real time [26]. In this context, zebrafish is a vertebrate model that provides a powerful in vivo screening of angiogenesis stimulators and inhibitors [27].

The aim of this work is to assess the potentiality of $T g(f l i-1: G F P)^{y l}$ zebrafish embryo assay for evaluating biomaterials effect on angiogenic promotion. The optical transparence of the developing embryos allows direct observation of blood vessels facilitating the study of angiogenesis. Furthermore, zebrafish is a well-established model organism with cellular and genetic regulatory mechanisms of angiogenesis very similar to those acting in mammalian species [22]. Copper containing MBG was chosen for the study since this type of mesoporous material has been reported to enhance angiogenic activity in vitro [18]. A comparison of the $\mathrm{Cu}$ containing material with a $\mathrm{Cu}$ free $\mathrm{MBG}$ has been performed to study the relevance of $\mathrm{Cu}$ over 
the other $\mathrm{Si}, \mathrm{Ca}$ and $\mathrm{P}$ ionic biodegradation products. Zebrafish angiogenesis assays are conducted by exposure to, or microinjection of, biomaterial dispersion into zebrafish embryos. These assays are followed by visual inspection of the intersegmental (ISV) and subintestinal (SIV) vessels pattern [28]. Although the effect of silicate ions on bone formation using zebrafish has been recently reported [29], to the author's knowledge, the zebrafish model has not been used to evaluate the angiogenic effects of bioceramics and bioactive silicate glasses ionic dissolution products.

\section{Materials and methods}

\subsection{Materials preparation}

MBG particles with a Si:Ca:P molar ratio of 80:15:5 were synthetized by the sol-gel method incorporating a non-ionic block polymer Pluronic®P123 (EO20-PO70-EO20) template, as previously reported [30]. Briefly, $4 \mathrm{~g}$ of the Pluronic ${ }^{\circledR}$ (435465, Sigma-Aldrich), $60 \mathrm{~mL}$ ethanol absolute (UN1170, AnalaR Normapur), $1 \mathrm{~mL} \mathrm{HCl}$ solution (PA-ACS-ISO, 37\%, Panreac), $1.37 \mathrm{~g}$ of $\mathrm{Ca}\left(\mathrm{NO}_{3}\right)_{2} \cdot 4 \mathrm{H}_{2} \mathrm{O}(\mathrm{C} 4955$, Sigma-Aldrich), $685 \mu \mathrm{L}$ triethyl phosphate (TEP, $\left(\mathrm{C}_{2} \mathrm{H}_{5} \mathrm{O}\right)_{3} \mathrm{PO}, 538728$, Sigma-Aldrich) and $7.125 \mathrm{~mL}$ tetraethyl orthosilicate (TEOS, $\mathrm{C}_{8} \mathrm{H}_{20} \mathrm{O}_{4} \mathrm{Si}$, Alfa-Aesar 99\%) were used. Cu-containing MBG (MBG-5Cu) was prepared by incorporating $5 \%$ mol Cu, replacing the corresponding amount of $\mathrm{Ca}$, using $0.48 \mathrm{~g}$ of $\mathrm{Cu}\left(\mathrm{NO}_{3}\right)_{2} \cdot 3 \mathrm{H}_{2} \mathrm{O}(61194$, Sigma-Aldrich). Sols were dried for 3 days at room temperature and aged for 3 days at $80{ }^{\circ} \mathrm{C}$. Obtained gels were finally heat treated using a heating rate of $1{ }^{\circ} \mathrm{C} \mathrm{min}^{-1}$ with two isothermal steps: $400{ }^{\circ} \mathrm{C}(1 \mathrm{~h})$ and $800{ }^{\circ} \mathrm{C}(2 \mathrm{~h})$. The final materials were sieved between 10 and $32 \mu \mathrm{m}$.

\subsection{Materials characterization}

The particle size distribution of the materials was measured with a Malvern Sizer Laser Diffraction (LD) instrument with an active beam length of $2.4 \mathrm{~mm}$ and a 300-RF lens. X-ray Diffraction (XRD) analysis was performed with a PANalytical X'Pert PRO diffractometer using $\mathrm{Cu}-\mathrm{K} \alpha$ radiation $(45 \mathrm{kV}, 40 \mathrm{~mA}, 0.154187 \mathrm{~nm})$. Small Angle XRD (SAXRD) measurements were carried out using a step size of $0.01^{\circ}$ and $1.5 \mathrm{~s}$ exposure time. Wide Angle XRD (WAXRD) patterns were recorded using a step size of $0.03^{\circ}$ and a $500 \mathrm{~s}$ exposure time. $\mathrm{N}_{2}$ 
adsorption-desorption isotherms were collected on a Micromeritics Tristar 3020 gas adsorption analyzer at $77 \mathrm{~K}$, after degassing at $523 \mathrm{~K}$ for $2 \mathrm{~h}$ in a nitrogen stream. The specific surface areas were calculated from the Barrett-Emmett-Teller (BET) method. Total pore volume was obtained from the $\mathrm{N}_{2}$ amount adsorbed at 0.99 relative pressure. The pore size distributions were calculated from the adsorption branch of the isotherm using the Barrett-Joyner-Halenda (BJH) method. The compositional analysis of materials were performed using X-ray Fluorescence (XRF) in an AXIOS WD-XRF, sequential Spectrometer (PANalytical). Fourier Transform Infrared (FTIR) spectra were collected in transmission configuration in the $4000-400 \mathrm{~cm}^{-1}$ range using $4 \mathrm{~cm}^{-1}$ interval in a Jasco 6200 spectrophotometer. Raman spectra were recorded by a dispersive Horiva Jobin Yvon LabRam HR800 Confocal Raman Microscope with a green laser (532.14 nm), working at $5 \mathrm{mV}$ power and using a 600 grooves $/ \mathrm{mm}$ grating. The microscope used a 100X objective with a confocal pinhole of $1000 \mu \mathrm{m}$. The Transmission Electron Microscopy (TEM) micrographs, Energy-Dispersive X-ray (EDX) analysis, and Selected Area Electron Diffraction (SAED) patterns were obtained using a Philips CM200 with a LaB6 filament as the electron source operated at $200 \mathrm{kV}$ coupled an X-ray Dispersive Energy Analysis System (EDX X-Max 80T, Oxford Instruments), and a CCD (Gatan) camera for image recording.

\subsection{Preparation of material extracts and dispersions for the biological experiments}

For cell culture in vitro assays dispersions of $\mathrm{MBG}$ and $\mathrm{MBG}-5 \mathrm{Cu}$ materials were prepared using two different concentrations, $100 \mathrm{mg} \mathrm{L}^{-1}$ and $300 \mathrm{mg} \mathrm{L}^{-1}$. The appropriate amount of the material was added in Dulbecco's modified Eagle's medium (DMEM). After 5 days at $37^{\circ} \mathrm{C}$, DMEM bare medium control and the material dispersions were filtered using a $0.2 \mu \mathrm{m}$ pore size sterile filter Dorsan (Syringe filters CA sterile) to eliminate MBG and MBG$5 \mathrm{Cu}$ particles. These preparations are named "extracts" along the following sections and were used as culture medium.

For the zebrafish embryo in vivo assays, two types of experiments were performed: exposure and microinjection. In both cases, suspensions of $300 \mathrm{mg} \mathrm{L}^{-1}$ and $3000 \mathrm{mg} \mathrm{L}^{-1}$ of materials were prepared just prior to the start of the experiment (day 0). Microparticles were dispersed in $\mathrm{E} 3$ embryo medium $(5 \mathrm{mM} \mathrm{NaCl}, 0.17 \mathrm{mM} \mathrm{KCl}, 0.33 \mathrm{mM} \mathrm{CaCl}, 0.33 \mathrm{mM}$ 
$\mathrm{MgSO}_{4}$, and $30 \mu \mathrm{L}$ of methylene blue $1 \%$ ), stirred for $1 \mathrm{~h}$ and treated with ultrasound for $15 \mathrm{~min}$ to promote homogeneity of the dispersion. $\mathrm{Cu}$ ion is also an environmental pollutant to aquatic environments when it is present at high concentration. Previous work indicate that lethal $50 \%$ (LC50) concentration for zebrafish is $\approx 0.1 \mathrm{mg} \mathrm{L}^{-1}[31,32]$. Accordingly, we use $0.05 \mathrm{mg} \mathrm{L}^{-1}$ $\mathrm{CuCl}_{2} .2 \mathrm{H}_{2} \mathrm{O}$ (C3279, Sigma-Aldrich) $\mathrm{L}^{-1} \mathrm{E} 3$ embryo medium solution $\left(0.015 \mathrm{mg} \mathrm{L}^{-1}\right.$ of $\mathrm{Cu}$ ionic) as positive control. These preparations are named "dispersions".

\subsection{Biodegradation}

To determine ionic degradation products of materials released during the 5 days of the embryos exposure assay, $3 \mathrm{~mL}$ of the experiment medium were collected every $24 \mathrm{~h}$ and analyzed by inductively coupled plasma atomic emission spectroscopy (ICP-AES) using a Horiba Jobin Yvon, Ultima 2 model equipped with a $40.68 \mathrm{MHz}$ RF generator, Czerny-Turner monochromator. Fresh E3 medium was also analyzed by ICP-AES as control sample.

\subsection{Cell Culture}

Bovine aortic endothelial cells (BAEC) were isolated from bovine aortic arches, as previously described [33], and maintained in Dulbecco's modified Eagle's medium (DMEM) containing glucose $\left(1 \mathrm{~g} \mathrm{~L}^{-1}\right)$, glutamine $(2 \mathrm{mM})$, penicillin $\left(50 \mathrm{IU} \mathrm{mL} \mathrm{L}^{-1}\right)$, streptomycin $(0.05 \mathrm{mg}$ $\mathrm{mL}^{-1}$ ) and amphotericin $\left(1.25 \mathrm{mg} \mathrm{L}^{-1}\right)$ supplemented with 10\% FBS (DMEM/10\% FBS). For cell culture maintenance, cells were placed in culture dishes and passages were performed when culture reached approximately $80 \%$ confluence ( 2 times per week) at a ratio of $1 / 5$ with fresh medium.

\subsection{Cell growth assay}

BAEC were seeded into $24-w e l l$ plates $\left(500 \mu \mathrm{L}\right.$ per well) at a density of $30000 \mathrm{cell} \cdot \mathrm{mL}^{-}$

${ }^{1}$ cultured in DMEM containing glucose $\left(1 \mathrm{~g} \mathrm{~L}^{-1}\right)$, glutamine $(2 \mathrm{mM})$, penicillin $\left(50 \mathrm{IU} \mathrm{mL} \mathrm{m}^{-1}\right)$, streptomycin $\left(50 \mu \mathrm{g} \mathrm{mL}^{-1}\right)$, and amphotericin $\left(1.25 \mu \mathrm{g} \mathrm{mL}^{-1}\right)$ and supplemented with $10 \%$ fetal bovine serum (FBS) under $\mathrm{CO}_{2}(5 \%)$ atmosphere and at $37^{\circ} \mathrm{C}$. Once the cells attached to the plate the DMEM 10\% FBS culture medium was removed and $600 \mu \mathrm{L}$ of the materials extracts or culture medium (control) were added and incubated at $37{ }^{\circ} \mathrm{C}$ for 7 days. Seven wells per condition were seeded initially and every day one well per condition was harvested and counted. 
Three independent experiments were performed per condition. Cells from wells were washed with phosphate buffered saline (PBS), cells were harvested in $0.5 \mathrm{~mL}$ by trypsinization and added to $10 \mathrm{~mL}$ counting solution (Isoton II Diluent, Beckman Coulter). Cell counting from each sample was performed using a particle size counter (Coulter Z2, Beckman Coulter) with Coulter Z2 AccuComp software. The average number of cells for each single day was then calculated and the values were used to plot a growth curve for each biodegradation extract. Fresh DMEM medium was also analyzed.

\subsection{Cell migration assay}

The migratory activity of BAEC was assessed using a "wound-healing" assay. Confluent monolayers in 6-well plates were wounded with pipet tips producing 2 perpendicular acellular lines. After washing with PBS, cells were supplied with $1.5 \mathrm{~mL}$ of the material extracts or culture medium (control). Wounded areas were photographed with a Nikon Eclipse Ti microscope equipped with a Nikon DS-Ri2. After an additional 4, 7 and 24 $\mathrm{h}$ of incubation, plates were observed under the microscope, and images were taken of the same areas recorded at time zero. Cell migration was determined by image analysis using the NIH Image J 1.6 software. The migration of BAEC into the cell-free area was calculated as the percentage of the initial wounded area (time 0 ) that had been colonized by the endothelial cells. To examine cell migration differences, cell free area of each wound was measured after each treatment time.

\subsection{Zebrafish embryo collection}

Zebrafish (Danio rerio) embryos were obtained from outcrosses of $T g(f l i 1: E G F P)^{y 1}$ parents. This transgenic line shows an EGFP-labelled vasculature useful for this study. The spawning adults were offspring of parents obtained from Zebrafish International Resource Center (ZIRC, Eugene, OR). Groups of 1 male and 2 females were mated in translucent plastic tanks and embryos were obtained within $30 \mathrm{~min}$ after the onset of light in the morning. The eggs were collected immediately after fertilization and washed several times for 1 min using a $0.5 \%$ bleach solution for disinfection. After this, clean eggs were incubated in E3 medium in a Petri dish at $28^{\circ} \mathrm{C}$. 
Fish were handled under National Laws (Directives 98/81/CE and 2000/54/CE, Law 32/2007 BOE 268, and Royal Decree Laws 178/2004 and 367/2010, Spain) by notification A/ES/12/I-22 and activity A/ES/12/24. Experiments were approved by UMA Bioethics commission under the grant BIO2014-56092-R.

\subsection{Zebrafish embryo exposure assay}

Twenty four hours-post-fertilization (hpf) $T g(F l i-1: E G F P)^{y 1}$ embryos were placed in 6well plate (10 fish per well using $3 \mathrm{~mL}$ of medium). Embryos were exposed by immersion in two different concentrations of material dispersions (four dispersions total from Section 2.3.), the positive control of $0.05 \mathrm{mg} \mathrm{L}^{-1} \mathrm{CuCl}_{2} 2 \mathrm{H}_{2} \mathrm{O}$ E3 embryo medium solution and the pure $\mathrm{E} 3$ embryo medium control. The exposure was carried out for 5 days at $28{ }^{\circ} \mathrm{C}$ where the medium was changed every $24 \mathrm{~h}$. A schematic diagram of the experimental procedure is illustrated in Figure 1. After 5 days of exposure, zebrafish were anesthetized (4\% Tricaine) and placed on a depression slide to observe gross morphological changes in the subintestinal vessels (SIVs) of the yolk sac region under a fluorescent microscope. Images were obtained using a Nikon Microphot-FX Fluorescence Research Microscope with a Nikon DS-L1 digital camera. Three parameters indicative of angiogenesis or vasodilation were measured: variation in the number of vessels, vessel thickness and the subintestinal venous plexus (SIVP) branching (angiogenic phenotype [34]). At least 20 embryos were immersed in each dispersion to analyze SIVs modification. All parameters were quantified with ImageJ, NIH Image J 1.6 software.

\subsection{Zebrafish embryo microinjection assay}

Twenty four hpf embryos in E3 medium were placed on a slide and microinjected under an optical microscope (Nikon Microphot-FX Fluorescence Research Microscope with a Nikon DS-L1 digital camera). $10 \mu \mathrm{L}$ of each test material concentration dispersion or control solution was back-filled into a pulled-glass micropipette. The micropipette was then attached to a micromanipulator and connected to a $\mathrm{N}_{2}$ tank. Using the micromanipulator, the tip of the micropipette was inserted into the embryo and a small volume was expelled from the tip using a

positive pressure $(650 \mathrm{hPa})$. Material dispersions and control solutions were injected at a constant volume of $4.18 \mathrm{~nL}(0.2 \mathrm{~mm}$ drop diameter) into the yolk sac region. Injected embryos 
were then placed in 6-well plate (10 fish per well using $3 \mathrm{~mL}$ of media) and incubated for 5 days at $28{ }^{\circ} \mathrm{C}$. Vascular changes (number of vessels, vessel thickness, and the SIVP branching [34]) with time were quantified by fluorescence microscopy image analysis. Figure 1 displays a schematic diagram of the embryos microinjection assay.

\subsection{Statistical analysis}

The acquired images were analyzed by ImageJ $1.50 \mathrm{i}$, which can be downloaded free of charge from the National Institutes of Health. Data were expressed as means \pm standard deviation (SD). Statistical analysis was performed using Statistical Package for the Social Sciences (SPSS) version 24 software. Statistical significance was performed in pairs between the experimental group and the "bare medium" control group and was calculated using a Student's $t$-test. An additional comparison in pairs between all groups of each experiment using the Student's $t$-test was also preformed (see supplementary information). Differences were considered significant when $p<0.05(*), p<0.01(* *)$ and $p<0.001(* * *)$.

\section{Results}

\subsection{Materials characterization}

The physical characterization of the synthesized particles is displayed in Figure 2. The median particle size determined from the particle size distribution was 22 and $20 \mu \mathrm{m}$ for MBG and MBG-5Cu respectively. The chemical composition was analysed using XRF (Table 1) confirming the incorporation of a $6.4 \%$ (molar ratio) of cooper for the MBG-5Cu material in good agreement with the $5 \%$ molar nominal ratio as calculated for the synthesis reactive precursors.

WAXRD pattern of the MBG exhibits a broad peak centred at $2 \Theta \approx 23^{\circ}$ which is characteristic of amorphous glass materials. For MBG-5Cu, two additional incipient diffraction peaks matched with (002) and (111) CuO phase crystal planes (JCPDS 48-1548) are detected. SAXRD analysis for both materials shows a well-resolved main diffraction peak characteristic of nanopore mesostructure [30]. The main (100) MBG-5Cu peak intensity decreases and shifts 
to a higher 2-theta degree when compared to the $\mathrm{Cu}$ free MBG. This suggest a loss of nanopore order. $\mathrm{N}_{2}$ adsorption-desorption isotherms for $\mathrm{MBG}$ and $\mathrm{MBG}-5 \mathrm{Cu}$ show the typical hysteresis loops characteristic of capillary condensation occurring in mesoporous materials. This observation confirms preservation of a well-ordered mesostructure upon the addition of copper with an average pore diameter of $3.7 \mathrm{~nm}$ (Figure 2d). In good correlation with SAXRD analysis, glasses containing $\mathrm{Cu}$ has a significant decrease in the specific surface area, $\mathrm{S}_{\mathrm{BET}}$, pore size, and total pore volume (Table 2).

The Raman spectrum for the MBG material shows main bands at 800, 956 and 1080 $\mathrm{cm}^{-1}$, corresponding respectively to $\mathrm{Si}-\mathrm{O}-\mathrm{Si}$ bending, $\mathrm{Si}-\mathrm{O}-\mathrm{NBO}$ stretching, and $\mathrm{Si}-\mathrm{O}-\mathrm{Si}$ asymmetric stretching vibrations [35-38]. Also, characteristic of sol-gel-derived silicate glasses, a broad band centred at $440 \mathrm{~cm}^{-1}$ ascribed to of Si-O-Si bending $\left(\omega_{1}\right)$ in $\geq 5$ fold rings of the silica network is found. The so-called defect lines labelled $\mathrm{D}_{1}$ and $\mathrm{D}_{2}$ are associated to the planar four- and three-membered rings, respectively [35,38]. In addition to this, new bands at 296, 344, 629 and $1130 \mathrm{~cm}^{-1}$, corresponding to $\mathrm{CuO}$ phase, are clearly detected for MBG-5Cu $[39,40]$. Also noteworthy is the shift to higher wavenumber of the sharp Si-O-Si band at 494 and 603 $\mathrm{cm}^{-1}$ as well as the band broadening of the Si-O-Si bending at $796 \mathrm{~cm}^{-1}$, Si-O-NBO at $956 \mathrm{~cm}^{-1}$ and $\mathrm{Si}-\mathrm{O}-\mathrm{Si}$ at $1081 \mathrm{~cm}^{-1}$ asymmetric stretching assignations. These variations have been considered an indication of copper silicate formation [41,42]. FT-IR analysis of materials exhibits typical Si-O-Si bonds vibrational modes characteristic of BGs. Main Si-O-Si stretching vibration in the (1000-1300 $\left.\mathrm{cm}^{-1}\right)$ range, Si-O-Si bending vibration at $800 \mathrm{~cm}^{-1}$ and the Si-O-Si rocking vibrations at $460 \mathrm{~cm}^{-1}$ [37]. Related to MBG spectrum, the main observed difference for MBG-5Cu is a higher definition of the band at $\approx 950 \mathrm{~cm}^{-1}$, which suggests some contribution of Si-O-NBO and Si-O-Cu bonds vibrations $[43,44]$.

The TEM micrographs, EDX analysis and SAED patterns of the MBG and MBG-5Cu are presented in Figure 3. The presence of well-ordered mesoporous channels of MBG is confirmed with a pore channel size diameter of approximately $4 \mathrm{~nm}$, as measured by physisorption (Table 2). EDX analysis (Figure 3) confirms the $\mathrm{Si}, \mathrm{Ca}, \mathrm{P}$ and $\mathrm{Cu}$ composition. 
Signal corresponding to $\mathrm{Ni}$ is caused by the use of nickel supporting grids. Figures $3 \mathrm{c}$ and $3 \mathrm{e}$ correspond to two different type areas observed for the MBG-5Cu material. Figure $3 \mathrm{c}$ shows a homogeneous zone with round dark features $10-50 \mathrm{~nm}$ in diameter decorating the mesostructured substrate. Although no diffraction spots were detected by SAED analysis in this area, $\mathrm{Cu}$ presence is confirmed by EDX (Figure 3d). Figure 3e presents the other characteristic type area showing a big crystal within 50-100 $\mathrm{nm}$ range size. EDX analysis of this area indicates higher copper content in this zone.

\subsection{Materials biodegradation}

The materials ionic product dissolution released to the medium during the 5 days exposure of the in vivo assay for the $\mathrm{CuCl}_{2} 2 \mathrm{H}_{2} \mathrm{O}$ positive control sample and the two studied material concentrations $300 \mathrm{mg} \mathrm{L}^{-1}$ and $3000 \mathrm{mg} \mathrm{L}^{-1}$ are compiled in Table 3. As expected, greater material content in the media lead to higher ionic concentration in the exposure media. Results indicate that $\mathrm{Cu}$ was released into the media at 0.005 and $0.171 \mathrm{mg} \mathrm{L}^{-1}$ respectively for the $300 \mathrm{mg} \mathrm{L}^{-1}$ and $3000 \mathrm{mg} \mathrm{L}^{-1}$ material dispersions. The amount of degradation after 5 days was determined to be 4.04 wt. $\%$ and 4.79 wt. \% for MBG and MBG-5Cu respectively. These values were calculated based on the silicon concentration in solution (determined by ICP-AES), as silicon is the major structural component of the glass.

\subsection{Cell growth assay}

Figure 4 displays the cell growth measured up to 7 days of culture in the presence of MBG and MBG-5Cu extracts for the two studied concentrations (100 and $\left.300 \mathrm{mg} \mathrm{L}^{-1}\right)$ in comparison with the control group. On the one hand, comparing growth curves of the control group with each experimental group, $100 \mathrm{mg} \mathrm{L}^{-1} \mathrm{MBG}$ extract produced an increase of the cell population growth. $300 \mathrm{mg} \mathrm{L}^{-1} \mathrm{MBG}$ and $300 \mathrm{mg} \mathrm{L}^{-1}$ MBG-5Cu extracts induced a similar trend up to the fifth day, but after 7 days the cell population growth for $300 \mathrm{mg} \mathrm{L}^{-1} \mathrm{MBG}-5 \mathrm{Cu}$ extract was significant lower than in the control group $(p<0.01)$. On the other hand, $100 \mathrm{mg} \mathrm{L}^{-1} \mathrm{MBG}-$ $5 \mathrm{Cu}$ extract also produced an increase of cell population growth between days 3 and 6 . 


\subsection{Cell migration assay}

Cell distributions examined after 4 and $7 \mathrm{~h}$ wound healing are presented in comparison with the control group in Figure 5. After $7 \mathrm{~h}$, all groups of BAEC cultures show higher cell migration in comparison with the bare medium control.

\subsection{Zebrafish embryo exposure assay}

At $24 \mathrm{hpf}$, embryos were collected and exposed to studied dispersions. An increase in the number and thickness of SIVs, was found in the yolk sac region of embryos treated for 5 days with $300 \mathrm{mg} \mathrm{L}^{-1} \mathrm{MBG}-5 \mathrm{Cu}$ dispersion with respect to those parameters in bare medium control group embryos (Figure 6). Average number and thickness of SIVs was measured for all the studied groups as listed in Table 4. The entire distribution of SIVs thicknesses is presented in Figure 7.

Results in Table 4 indicate significant differences with respect to the bare medium control group in the SIVs number for those groups exposed to the $300 \mathrm{mg} \mathrm{L}^{-1}$ materials dispersions. Among all assayed groups, embryos exposed to $300 \mathrm{mg} \mathrm{L}^{-1} \mathrm{MBG}-5 \mathrm{Cu}$ material show the highest increase in both number and thickness of SIVs. As shown in Table 4, a significant increase of the average SIVs number (from 6.2 to 10.6) and thickness (from 6.03 to $7.58 \mu \mathrm{m})$ is observed. However, SIVs number and thickness of the $3000 \mathrm{mg} \mathrm{L}^{-1} \mathrm{MBG}-5 \mathrm{Cu}$ material-exposed embryos do not show this behavior.

Figure 8a shows a characteristic "angiogenic" phenotype of new SIVP vessel formation [34], branching and fusion found in zebrafish embryos after 5 day-exposure to positive control. Figure $8 \mathrm{~b}$ displays a quantification of zebrafish specimens showing this phenotype in all experimental groups. Besides the positive control, which promotes the formation of this “angiogenic" phenotype $(p<0.05), 300 \mathrm{mg} \mathrm{L}^{-1} \mathrm{MBG}-5 \mathrm{Cu}(p<0.01)$ material dispersion group show the highest formation percentage.

\subsection{Zebrafish embryo microinjection assay}


Yolk sacs were examined after 5 days of microinjection. Average SIVs number and thickness were measured in embryos of all the studied groups as listed in Table 5. In comparison with the bare medium control, no significant differences in the SIVs number were detected for the groups. The SIVs thickness measurements are shown in Figure 9. A slight increase is observed in embryos injected with the $300 \mathrm{mg} \mathrm{L}^{-1} \mathrm{MBG}$ and MBG-5Cu and $3000 \mathrm{mg}$ $\mathrm{L}^{-1}$ MBG-5Cu material dispersions groups. It is worth pointing out that experiments performed using the highest concentration $\left(3000 \mathrm{mg} \mathrm{L}^{-1}\right)$ of material dispersions showed a visible degeneration in the overall appearance of some embryos. Table 6 shows a quantification of the number of specimens showing moderate kyphosis being relevant in the case of the $3000 \mathrm{mg} \mathrm{L}^{-1}$ MBG-5Cu material dispersion.

\section{Discussion}

Bioactive glass has been proposed for bone regeneration therapies [2]. Beside osteogenesis, these therapies require synergistic pro-angiogenic $[45,46]$ and immunomodulatory [47] effects. In this article, we have exclusively studied the pro-angiogenic effect of $\mathrm{Cu}$, something well-established molecularly [13]. For this, $6.4 \%$ mol $\mathrm{Cu}$-containing $\mathrm{MBG}$ and $\mathrm{Cu}$ free MBG materials were prepared and characterized. The ionic biodegradation products were analyzed in relation to their angiogenic properties in vitro, using BAEC and in vivo using a zebrafish embryo assay. The potentiality of $T g(f l i-1: G F P)^{y l}$ zebrafish embryo assay has been essayed for evaluating not only the effect of biomaterials on angiogenic promotion but also the relevance of $\mathrm{Cu}$ on this effect over the other $\mathrm{Si}, \mathrm{Ca}$ and $\mathrm{P}$ ionic bioactive glass biodegradation products. In our in vivo experiments, copper ions are released by dopped-bioactive glass from extra-embryonic solutions. Angiogenic effects are studied over vessels surrounding these extraembryonic tissues where osteogenesis or inflammation is absent or highly reduced.

MBG and MBG-5Cu characterization using XRD, $\mathrm{N}_{2}$ physisorption, and TEM confirms the existence of a well-ordered mesoporous structure in both materials although some important 
nanostructural distortions are observed when copper is added to the $\mathrm{SiO}_{2}-\mathrm{CaO}-\mathrm{P}_{2} \mathrm{O}_{5}$ base composition. The incorporation of $\mathrm{Cu}$ to the $\mathrm{MBG}$ composition decreases the surface area to $239 \mathrm{~m}^{2} \cdot \mathrm{g}^{-1}$ and the mesopore size to $3.7 \mathrm{~nm}$. However, these lower values are still well within the $200-350 \mathrm{~m}^{2} \cdot \mathrm{g}^{-1}$ range surface area and $3-5 \mathrm{~nm}$ mesopore size which are right values to adsorb a number of biomolecules, such as drugs, antibiotics and growth factors [48]. Replacing $\mathrm{Ca}$ by $\mathrm{Cu}$ may somehow disrupt the inorganic phase polycondensation during supramolecular hybrid self-assembly process. Also, the silica network structural distortions detected for the MBG-5Cu material by FT-IR, Raman analysis and TEM micrographs suggest that $\mathrm{Cu}$ is a glass structure modifier. Hence, additionally to the silicate FT-IR spectra essential features at 450 , 800 and $1100 \mathrm{~cm}^{-1}$, a new shoulder at $970 \mathrm{~cm}^{-1}$ can be assigned to Si-O-NBO and Si-O-Cu new bonds formation [42]. Furthermore, some authors have attributed the shift to higher wavenumbers of the Raman sharp Si-O-Si rocking band, as well as the band broadening of the Si-O-Si bending, $\mathrm{Si}-\mathrm{O}-\mathrm{NBO}$ and $\mathrm{Si}-\mathrm{O}-\mathrm{Si}$ asymmetric stretching adscriptions to the formation of copper silicate $[41,42]$. TEM observations indicate that $\mathrm{Cu}$ decreases the mesoporous channels order in the material as well as produces stronger contrast features decorating the mesostructured matrix. EDX analysis of these areas indicates the presence of copper. In some of the observed areas, this copper would be in non-crystalline form as shown by the SAED patterns. In addition to this, formation of big crystal aggregates in the 40-130 nm range is also found. The presence of these crystalline particles matched with the $\mathrm{CuO}$ phase identified by XRD.

Moreover, the still high specific surface area and porosity that a glass material with this structure modifier element shows would result in high reactivity and degradation in an aqueous environment as it has been reported previously for other lattice modifiers $[49,50]$. This high reactivity is in fact the main advantage for their application in bone repair. The ionic products of the implanted material delivered to the physiological media lead to crystallisation of hydroxyapatite, which act as a biomimetic matrix at the implant interface. Various studies have also demonstrated that the addition of $\mathrm{Sr}, \mathrm{Zr}, \mathrm{Fe}, \mathrm{Zn}, \mathrm{Mg}$ and $\mathrm{Cu}$ trace elements to MBG materials can lead to controlled 
degradation and positively influence therapeutic purposes [51]. In this study, biodegradation studies of materials indicate that copper ions are delivered to the media. Besides, when using the low concentration material dispersions of $300 \mathrm{mg} \mathrm{L}^{-1}$, a slightly higher $\mathrm{Si}, \mathrm{Ca}$ and $\mathrm{P}$ ion concentration was observed for MBG-5Cu in comparison with $\mathrm{Cu}$ free MBG.

The success of tissue engineering strategies is dependent on the formation of an effective blood supply to ensure cell viability following scaffold engraftment. Previously, BGs have been reported to promote angiogenesis in vitro and in vivo [52-54]. 45S5® Bioglass increased secretion of VEGF and bFGF gene expression in fibroblasts, the proliferation of endothelial cells and formation of endothelial tubules in vitro [7], as well as enhancement of vascularization in vivo in a rat model [52]. Recently, studies showed that the released Si ions from silicate-based bioceramics stimulate in vitro and in vivo angiogenesis $[55,56]$. The most widespread idea is that the angiogenic effect is closely related to the pronounced Si-ion release. More recently, it has been found that calcium increased expression of pro-angiogenic factors [57]. On the other side, $\mathrm{Cu}$ has also been shown to influence a number of factors involved in the initiation of angiogenesis, including VEGF [12], bFGF [58], and angiogenin [59]. The angiogenic activity of $\mathrm{Cu}$ has been attributed to stabilization of HIF-1 $\alpha$ and inhibition of PHDmediated hydroxylation, under normoxic conditions [13]. Cu-dependent enhancement of HIF-1 $\alpha$ activity positively influences the vasodilation of pre-existing blood vessels, which represents the first stage in angiogenesis [60].

During the last decades, the understanding of cellular and molecular mechanisms involved in angiogenesis process has been matter of intense research. Bovine aortic endothelial cells (BAEC) are frequently used as an in vitro model for testing pro-/anti-angiogenic features of tested compounds. In the present study we have used BAEC to evaluate the effect of the ionic product of MBG and MBG-5Cu on cell growth and cell migratory capacity. Cell culture showed that the ionic dissolution products of $\mathrm{MBG}$ and $\mathrm{MBG}-5 \mathrm{Cu}$ are not toxic to BAEC. In comparison with the bare medium control, a mild proliferation promotion could be measured in the exponential phase of growth curves (between days 3 and 5/6) for both materials using the 
$100 \mathrm{mg} \mathrm{L}^{-1}$, whereas after 7 days of incubation the stationary phase of growth was reached. In contrast, $300 \mathrm{mg} \mathrm{L}^{-1}$ extracts produced a significant decrease of cell population in the 7 th day of incubation, thus indicating a possible cytostatic effect at such a high concentration of MBG. Angiogenesis is a multistep process and, therefore, is susceptible to modulation in each of its steps, being one of the first cell migration. We rely on the fact that endothelial cells are mostly quiescent in the adulthood and, for angiogenesis to occur, activation of the endothelium is necessary with the consequent acquisition of both proliferative and migratory capacity of endothelial cells towards the source of the proangiogenic signal.

The wound-healing assay is currently used in specialized literature [61-63] and is chosen because performed in short times ( 4 and 7 hours), gap occupation by cells is exclusively due to their migration and not to their proliferation, since there is not sufficient time going to complete a cell cycle. Migration assay showed that material extracts using both 100 and $300 \mathrm{mg}$ $\mathrm{L}^{-1}$ concentrations were able to increase the migratory rate of BAEC, suggesting a proangiogenic effect. However, after 7 days, the $300 \mathrm{mg} \mathrm{L}^{-1} \mathrm{MBG}-5 \mathrm{Cu}$ extract induces a decrease in cell growth. The differences in results obtained in both proliferation and migration assays are not surprising, since they test effects on two different steps of the angiogenic process at two very different time ranges. Cell growth curves show a possible effect on cell division, with the consequent differences in cell density in a period of various days. The wound healing assay shows the effects on cell migration, based on cellular mechanisms that are different to those related with cell division. This migration assay is performed in short incubation times (in the case of the present work, 4-7 h) to assess the re-occupation of the wounded area due to cell migration and not to cell proliferation.

Our data demonstrates that $\mathrm{Cu}$ dissolution of $\mathrm{MBG}-5 \mathrm{Cu}$ material in $\mathrm{E} 3$ medium does occur at 0.005 and $0.171 \mathrm{mg} \mathrm{L}^{-1}$ using respectively 300 and $3000 \mathrm{mg} \mathrm{L}^{-1}$ of material dispersion. Results of embryos exposure indicate that a significant increase in the number and thickness of SIVs is induced by both MBG and MBG-5Cu material at the lowest concentration dispersion of $300 \mathrm{mg} \mathrm{L}^{-1}$. The embryos exposed to the MBG-5Cu material show the highest SIVs number (from 6.2 to 10.6) and thickness (from 6.03 to $7.58 \mu \mathrm{m}$ ) increase in comparison with bare 
medium control. Furthermore, the "angiogenic" SIVP phenotype is particularly enhanced for the $300 \mathrm{mg} \mathrm{L}^{-1}$ MBG-5Cu material dispersion (corresponding to $0.005 \mathrm{mg} \mathrm{Cu} \mathrm{L}^{-1}$ ) and the positive copper salt control groups. These results suggest not only an important angiogenic effect of ionic copper but also a synergistic pro-angiogenic effect between $\mathrm{Cu}$ ions and the other $\mathrm{Si}, \mathrm{Ca}$ and $\mathrm{P}$ ions released from MBG. The presented data reinforce previous in vitro studies using endothelial cell cultures, which revealed that extracts media containing $\mathrm{Cu}$ doped calcium silicate extracts possessed stronger stimulatory effects over angiogenic growth factors than bare calcium silicate ceramics. This property finally resulted in better stimulatory effects on vascularization [64].

It is further interesting the significant increase of SIVs parameters observed for MBG $\mathrm{Cu}$ free material using the $3000 \mathrm{mg} \mathrm{mL}^{-1}$ concentration. This result indicates that the highest $\mathrm{Si}$, $\mathrm{Ca}$ and $\mathrm{P}$ MBG ionic product concentration essayed, in the absence of $\mathrm{Cu}$, show positive effect for angiogenesis promotion, but this effect is reversed when $\mathrm{Cu}$ is also present at $0.171 \mathrm{mg} \mathrm{L}^{-1}$ concentration. The performed experiment reveals that this ionic $\mathrm{Cu}$ concentration has exceeded adequate doses for SIVP angiogenic promotion. This result will agree previous referred toxic concentration for zebrafish of $\approx 0.1 \mathrm{mg} \mathrm{L}^{-1}[31,32]$.

Besides, embryos microinjected with both material dispersions show an increase of SIVs thickness although a visible degeneration in the overall appearance of the fish is also observed using the higher concentration $\left(3000 \mathrm{mg} \mathrm{L}^{-1}\right)$. This degeneration is more intense in the case of the MBG-5Cu, suggesting an additional $\mathrm{Cu}$ toxic effect. Previous work in zebrafish model indicate that the risk of neurodegenerative diseases can be produced exceeding an optimal ionic $\mathrm{Cu}$ concentration [65].

Mild inflammation has been shown to stimulate natural regenerative responses after disorders affecting tooth [66], bone [67] or dermal connective tissue [68]. We have not observed clear signs of inflammation in extra-embryonic tissues, such as accumulation of cells in perivitelline tissues, and only cardiac edema has been rarely found (data not shown), potentially as a further sign of toxic effects at high $\mathrm{Cu}$ concentrations. Whether $\mathrm{Cu}$ toxicity is associated to 
an intense inflammation or induced pro-angiogenesis is the effect of a mild inflammatory response to low $\mathrm{Cu}$ concentrations have not been tested here.

To our knowledge, this is the first time that zebrafish in vivo assays are used to evaluate angiogenic activity of ionic dissolution products from MBG materials. The data obtained demonstrates that zebrafish model is an effective system to evaluate the effects of bioactive ions in short time-consuming protocols and facilities.

\section{Conclusions}

In this study, $\mathrm{MBG}$ and $\mathrm{MBG}-5 \mathrm{Cu}$ materials ionic products, delivered to the physiological zebrafish model media, significantly enhanced angiogenesis in comparison with the control groups. The exposure and microinjection embryos indicate that the ionic dissolution products delivered from the $\mathrm{MBG}(\mathrm{Cu}$ free) material at the lower dispersion concentration (300 $\mathrm{mg} \mathrm{L}^{-1}$ ) promote vessels vasodilation increasing SIVs number and thickness. The highest proangiogenic effect is observed using $300 \mathrm{mg} \mathrm{L}^{-1}$ MBG-5Cu material dispersion using the embryos exposure assay. Both type of in vivo assays (exposure and microinjection) indicate that MBG and MBG-5Cu at high concentration can be toxic. Interestingly, the complete set of results suggests the delivery of $\mathrm{Cu}$ ions may exhibit a synergic effect with $\mathrm{Si}, \mathrm{Ca}$, and $\mathrm{P}$ ions in angiogenesis stimulation. In addition, in vitro cell culture showed that the MBG and MBG-5Cu extracts promoted cell viability and migration.

\section{Acknowledgements}

The authors gratefully acknowledge the financial support provided by the Andalusian Ministry of Economy, Science and Innovation (Proyecto Excelencia Grant no. P10-CTS-6681) and Spanish Ministry of Economy and Competitivity (BIO2014-56092-R). LBRS acknowledges the CONACYT-Mexico Fellowship PhD Program. Authors thank Dra. Ana R. Quesada for suggestions on experiments. 


\section{References}

[1] H. Naderi, M.M. Matin, A.R. Bahrami, Critical issues in tissue engineering: biomaterials, cell sources, angiogenesis, and drug delivery systems, J. Biomater. Appl. 26 (2011) 383-417. doi:10.1177/0885328211408946.

[2] M.N. Rahaman, D.E. Day, B. Sonny Bal, Q. Fu, S.B. Jung, L.F. Bonewald, A.P. Tomsia, Bioactive glass in tissue engineering, Acta Biomater. 7 (2011) 2355-2373. doi:10.1016/j.actbio.2011.03.016.

[3] R.A. Perez, S.J. Seo, J.E. Won, E.J. Lee, J.H. Jang, J.C. Knowles, H. Kim, Therapeutically relevant aspects in bone repair and regeneration, Mater. Today. 18 (2015) 573-589. doi:10.1016/j.mattod.2015.06.011.

[4] I.D. Xynos, A.J. Edgar, L.D.K. Buttery, L.L. Hench, J.M. Polak, Gene-expression profiling of human osteoblasts following treatment with the ionic products of Bioglass ${ }^{\circledR}$ 45S5 dissolution, J. Biomed. Mater. Res. 55 (2001) 151-157. doi:10.1002/10974636(200105)55:2<151::AID-JBM1001>3.0.CO;2-D.

[5] L.L. Hench, I.D. Xynos, J.M. Polak, Bioactive glasses for in situ tissue regeneration, J. Biomater. Sci. Polym. Ed. 15 (2004) 543-562. doi:10.1163/156856204323005352.

[6] R.M. Day, Bioactive glass stimulates the secretion of angiogenic growth factors and angiogenesis in vitro, Tissue Eng. 11 (2005) 768-777. doi:10.1089/ten.2005.11.768.

[7] A.A. Gorustovich, J.A. Roether, A.R. Boccaccini, Effect of bioactive glasses on angiogenesis: a review of in vitro and in vivo evidences, Tissue Eng. Part B. 16 (2010) 199-207. doi:10.1089/ten.teb.2009.0416.

[8] H. Li, K. Xue, N. Kong, K. Liu, J. Chang, Silicate bioceramics enhanced vascularization and osteogenesis through stimulating interactions between endothelia cells and bone marrow stromal cells, Biomaterials. 35 (2014) 3803-3818. doi:10.1016/j.biomaterials.2014.01.039.

[9] K.S. Raju, G. Alessandri, M. Ziche, P.M. Gullino, Ceruloplasmin, copper ions, and angiogenesis, J. Natl. Cancer Inst. 69 (1982) 1183-1188.

[10] A. Hoppe, N.S. Güldal, A.R. Boccaccini, A review of the biological response to ionic dissolution products from bioactive glasses and glass-ceramics, Biomaterials. 32 (2011) 2757-2774. doi:10.1016/j.biomaterials.2011.01.004.

[11] G. Hu, Copper stimulates proliferation of human endothelial cells under culture, J. Cell. Biochem. 69 (1998) 326-335.

[12] C.K. Sen, S. Khanna, M. Venojarvi, P. Trikha, E.C. Ellison, T.K. Hunt, S. Roy, Copperinduced vascular endothelial growth factor expression and wound healing, Am. J. Physiol. 282 (2002) H1821-H1827. doi:10.1152/ajpheart.01015.2001.

[13] F. Martin, T. Linden, D.M. Katschinski, F. Oehme, I. Flamme, C.K. Mukhopadhyay, K. Eckhardt, J. Tröger, S. Barth, G. Camenisch, R.H. Wenger, Copper-dependent activation of hypoxia-inducible factor ( HIF ) 1 : implications for ceruloplasmin regulation, Blood. 105 (2005) 4613-4619. doi:10.1182/blood-2004-10-3980. 
[14] C. Stähli, M. James-Bhasin, A. Hoppe, A.R. Boccaccini, S.N. Nazhat, Effect of ion release from $\mathrm{Cu}$-doped 45S5 Bioglass ${ }^{\circledR}$ on 3D endothelial cell morphogenesis, Acta Biomater. 19 (2015) 15-22. doi:10.1016/j.actbio.2015.03.009.

[15] M.L. Ramiro-Gutiérrez, L. Santos-Ruiz, S. Borrego-González, J. Becerra, A. DíazCuenca, In vitro stimulation of MC3T3-E1cells and sustained drug delivery by a hierarchical nanostructured SiO2-CaO-P2O5 scaffold, Microporous Mesoporous Mater. 229 (2016) 31-43. doi:10.1016/j.micromeso.2016.04.018.

[16] M.L. Ramiro-Gutiérrez, J. Will, A.R. Boccaccini, A. Díaz-Cuenca, Reticulated bioactive scaffolds with improved textural properties for bone tissue engineering: Nanostructured surfaces and porosity, J. Biomed. Mater. Res. - Part A. 102 (2014) 2982-2992. doi:10.1002/jbm.a.34968.

[17] L.B. Romero-Sánchez, S. Borrego-González, A. Díaz-Cuenca, High surface area biopolymeric-ceramic scaffolds for hard tissue engineering, Biomed. Phys. Eng. Express. 3 (2017) 035012. doi:10.1088/2057-1976/aa7001.

[18] C. Wu, Y. Zhou, M. Xu, P. Han, L. Chen, J. Chang, Y. Xiao, Copper-containing mesoporous bioactive glass scaffolds with multifunctional properties of angiogenesis capacity, osteostimulation and antibacterial activity, Biomaterials. 34 (2013) 422-433. doi:10.1016/j.biomaterials.2012.09.066.

[19] S.N. Rath, A. Brandl, D. Hiller, A. Hoppe, U. Gbureck, R.E. Horch, A.R. Boccaccini, U. Kneser, Bioactive copper-doped glass scaffolds can stimulate endothelial cells in coculture in combination with mesenchymal stem cells, PLoS One. 9 (2014) 1-24. doi:10.1371/journal.pone.0113319.

[20] C.A. Staton, M.W.R. Reed, N.J. Brown, A critical analysis of current in vitro and in vivo angiogenesis assays, Int. J. Exp. Pathol. 90 (2009) 195-221. doi:10.1111/j.13652613.2008.00633.x.

[21] A. Schuermann, C.S.M. Helker, W. Herzog, Angiogenesis in zebrafish, Semin. Cell Dev. Biol. 31 (2014) 106-114. doi:10.1016/j.semcdb.2014.04.037.

[22] G. Kari, U. Rodeck, A.P. Dicker, Zebrafish: an emerging model system for human disease and drug discovery, Clin. Pharmacol. Ther. 82 (2007) 70-80. doi:10.1038/sj.clpt.6100223.

[23] K. Dooley, L.I. Zon, Zebrafish: a model system for the study of human disease, Curr. Opin. Genet. Dev. 10 (2000) 252-256. doi:10.1016/S0959-437X(00)00074-5.

[24] F. Melet, B. Motro, D.J. Rossi, L. Zhang, A. Bernstein, Generation of a novel Fli-1 protein by gene targeting leads to a defect in thymus development and a delay in friend virus-induced erythroleukemia, Mol Cell Biol. 16 (1996) 2708-2718. http://www.ncbi.nlm.nih.gov/pubmed/8649378.

[25] M.A. Thompson, D.G. Ransom, S.J. Pratt, H. MacLennan, M.W. Kieran, H.W. Detrich, B. Vail, T.L. Huber, B. Paw, A.J. Brownlie, A.C. Oates, A. Fritz, M.A. Gates, A. Amores, N. Bahary, W.S. Talbot, H. Her, D.R. Beier, J.H. Postlethwait, L.I. Zon, The cloche and spadet ail genes differentially affect hematopoiesis and vasculogenesis, Dev. Biol. 197 (1998) 248-269. doi:10.1006/dbio.1998.8887. 
[26] N.D. Lawson, B.M. Weinstein, In vivo imaging of embryonic vascular development using transgenic zebrafish, Dev Biol. 248 (2002) 307-318. doi:S0012160602907116 [pii].

[27] C. Parng, W.L. Seng, C. Semino, P. McGrath, Zebrafish: a preclinical model for drug screening, Assay Drug Dev. Technol. 1 (2002) 41-48.

[28] S. Childs, J. Chen, D.M. Garrity, M.C. Fishman, Patterning of angiogenesis in the zebrafish embryo, Development. $129 \quad$ (2002) 973-982. http://dev.biologists.org/content/129/4/973.full.

[29] M. Montazerolghaem, L. Nyström, H. Engqvist, M. Karlsson Ott, Zebrafish: a possible tool to evaluate bioactive ions, Acta Biomater. 19 (2015) 10-14. doi:10.1016/j.actbio.2015.03.010.

[30] X. Yan, C. Yu, X. Zhou, J. Tang, D. Zhao, Highly ordered mesoporous bioactive glasses with superior in vitro bone-forming bioactivities, Angew Chem Int Ed. 43 (2004) 59805984. doi:10.1002/anie.200460598.

[31] R.J. Griffitt, J. Luo, J. Gao, J. Bonzongo, D.S. Barber, Effects of particle composition and species on toxicity of metallic nanomaterials in aquatic organisms, Environ. Toxicol. Chem. 27 (2008) 1972-1987. doi:10.1897/08-002.1.

[32] J. Chang, G. Ichihara, Y. Shimada, S. Tada-Oikawa, J. Kuroyanagi, B. Zhang, Y. Suzuki, R. Sehsah, M. Kato, T. Tanaka, S. Ichihara, Copper oxide nanoparticles reduce vasculogenesis in transgenic zebrafish through down-regulation of vascular endothelial growth factor expression and induction of apoptosis., J. Nanosci. Nanotechnol. 15 (2015) 2140-2147. doi:10.1166/jnn.2015.9762.

[33] D. Gospodarowicz, J.S. Moran, Growth factors in mammalian cell culture, Annu Rev Biochem. 45 (1976) 531-558.

[34] M. Goi, S.J. Childs, Patterning mechanisms of the sub-intestinal venous plexus in zebrafish, Dev. Biol. 409 (2016) 114-128. doi:10.1167/iovs.07-1072.ComplementAssociated.

[35] A.E. Geissberger, F.L. Galeener, Raman studies of vitreous $\mathrm{SiO} 2$ versus fictive temperature, Phys. Rev. B. 28 (1983) 3266-3271. doi:10.1103/PhysRevB.28.3266.

[36] P. González, J. Serra, S. Liste, S. Chiussi, B. León, M. Pérez-Amor, Raman spectroscopic study of bioactive silica based glasses, J. Non. Cryst. Solids. 320 (2003) 92-99. doi:10.1016/S0022-3093(03)00013-9.

[37] H. Aguiar, J. Serra, P. González, B. León, Structural study of sol-gel silicate glasses by IR and Raman spectroscopies, J. Non. Cryst. Solids. 355 (2009) 475-480. doi:10.1016/j.jnoncrysol.2009.01.010.

[38] G.S. Tienderson, M.E. Fleet, The structure of Ti silicate glasses by micro-Raman spectroscopy, Can. Mineral. 33 (1995) 399-408.

[39] H. Hagemann, H. Bill, W. Sadowski, E. Wlaker, M. Francois, Raman spectra of single crystal CuO, Solid State Commun. 73 (1990) 447-451. 
[40] W. Wang, Q. Zhou, X. Fei, Y. He, P. Zhang, G. Zhang, L. Peng, W. Xie, Synthesis of $\mathrm{CuO}$ nano- and micro-structures and their Raman spectroscopic studies, CrystEngComm. 12 (2010) 2232-2237. doi:10.1039/b919043k.

[41] D.A. Mckeown, I. Bell, C.C. Kim, Raman spectroscopy of silicate rings: benitoite and the three-membered ring, Phys. Rev. B. 48 (1993) 357-365.

[42] F. Pérez-Robles, F.J. García-Rodríguez, S. Jiménez-Sandoval, J. González-Hernández, Raman study of copper and iron oxide particles embedded in an $\mathrm{SiO} 2$ matrix, J. Raman Spectrosc. $\quad 30 \quad$ (1999) 1099-1104. doi:10.1002/(SICI)10974555(199912)30:12<1099::AID-JRS490>3.0.CO;2-0.

[43] R. Neumann, M. Levin-Elad, Metal oxide (TiO2, MoO3, WO3) substituted silicate xerogels as catalysts for the oxidation of hydrocarbons with hydrogen peroxide, J. Catal. 166 (1997) 206-217. doi:10.1006/jcat.1997.1479.

[44] M. Meibohm, H.H. Otto, W. Brockner, Vibrational spectra of copper polysilicate, CuSiO3, (2009) 1-9. http://arxiv.org/abs/0903.3901.

[45] R. Subbiah, M.P. Hwang, S.Y. Van, S.H. Do, H. Park, K. Lee, S.H. Kim, K. Yun, K. Park, Osteogenic/angiogenic dual growth factor delivery microcapsules for regeneration of vascularized bone tissue, Adv. Healthc. Mater. 4 (2015) 1982-1992. doi:10.1002/adhm.201500341.

[46] L. Xia, Z. Yin, L. Mao, X. Wang, J. Liu, X. Jiang, Z. Zhang, K. Lin, J. Chang, B. Fang, Akermanite bioceramics promote osteogenesis, angiogenesis and suppress osteoclastogenesis for osteoporotic bone regeneration, Sci. Rep. 6 (2016) 22005. doi:10.1038/srep22005.

[47] Q. Cui, A.S. Dighe, J.N. Irvine Jr, Combined angiogenic and osteogenic factor delivery for bone regenerative engineering, Curr. Pharm. Des. 19 (2013) 3374-3383. doi: $10.2174 / 1381612811319190004$.

[48] M. Vallet-Regí, Ordered mesoporous materials in the context of drug delivery systems and bone tissue engineering, Chem. - A Eur. J. 12 (2006) 5934-5943. doi:10.1002/chem.200600226.

[49] L.L. Hench, Bioactive Ceramics, Ann. N. Y. Acad. Sci. 523 (1988) 54-71. doi:10.1111/j.1749-6632.1988.tb38500.x.

[50] M. Vallet-Regí, Ceramics for medical applications, J. Chem. Soc. Dalt. Trans. (2001) 97-108. doi:10.1039/b007852m.

[51] C. Wu, J. Chang, Mesoporous bioactive glasses: structure characteristics, drug/growth factor delivery and bone regeneration application, Interface Focus. 2 (2012) 292-306. doi:10.1098/rsfs.2011.0121.

[52] L.C. Gerhardt, K.L. Widdows, M.M. Erol, C.W. Burch, J. a. Sanz-Herrera, I. Ochoa, R. Stämpfli, I.S. Roqan, S. Gabe, T. Ansari, A.R. Boccaccini, The pro-angiogenic properties of multi-functional bioactive glass composite scaffolds, Biomaterials. 32 (2011) 4096-4108. doi:10.1016/j.biomaterials.2011.02.032. 
[53] A. Arkudas, A. Balzer, G. Buehrer, I. Arnold, A. Hoppe, R. Detsch, P. Newby, T. Fey, P. Greil, R.E. Horch, A.R. Boccaccini, U. Kneser, Evaluation of angiogenesis of bioactive glass in the arteriovenous loop model, Tissue Eng. Part C Methods. 19 (2013) 479-486. doi:10.1089/ten.tec.2012.0572.

[54] M. Handel, T.R. Hammer, P. Nooeaid, A.R. Boccaccini, D. Hoefer, 45S5-Bioglass ${ }^{\circledR}$ based 3D-scaffolds seeded with human adipose tissue-derived stem cells induce in vivo vascularization in the CAM angiogenesis assay, Tissue Eng. Part A. 19 (2013) 27032712. doi:10.1089/ten.tea.2012.0707.

[55] W. Zhai, H. Lu, C. Wu, L. Chen, X. Lin, K. Naoki, G. Chen, J. Chang, Stimulatory effects of the ionic products from $\mathrm{Ca}-\mathrm{Mg}-\mathrm{Si}$ bioceramics on both osteogenesis and angiogenesis in vitro, Acta Biomater. 9 (2013) 8004-8014. doi:10.1016/j.actbio.2013.04.024.

[56] H. Li, J. Chang, Stimulation of proangiogenesis by calcium silicate bioactive ceramic, Acta Biomater. 9 (2013) 5379-5389. doi:10.1016/j.actbio.2012.10.019.

[57] H. Oliveira, S. Catros, C. Boiziau, R. Siadous, J. Marti-Munoz, R. Bareille, S. Rey, O. Castano, J. Planell, J. Am??d??e, E. Engel, The proangiogenic potential of a novel calcium releasing biomaterial: impact on cell recruitment, Acta Biomater. 29 (2016) 435-445. doi:10.1016/j.actbio.2015.10.003.

[58] Y. Shing, Heparin-copper biaffinity chromatography of fibroblast growth factors, J. Biol. Chem. 263 (1988) 9059-9062.

[59] F. Soncin, J.D. Guitton, T. Cartwright, J. Badet, Interaction of human angiogenin with copper modulates angiogenin binding to endothelial cells, Biochem. Biophys. Res. Commun. 236 (1997) 604-610. doi:10.1006/bbrc.1997.7018.

[60] E. Urso, M. Maffia, Behind the link between copper and angiogenesis: established mechanisms and an overview on the role of vascular copper transport systems, J. Vasc. Res. 52 (2015) 172-196. doi:10.1159/000438485.

[61] Q. Wu, T. Fang, H. Lang, M. Chen, P. Shi, G. Qi, X. Pang, Comparison of the proliferation, migration and angiogenic properties of human amniotic epithelial and mesenchymal stem cells and their effects on endothelial cells, Int. J. Mol. Med. (2017) 918-926. doi:10.3892/ijmm.2017.2897.

[62] X. Xiao, S. Xu, L. Li, M. Mao, J. Wang, Y. Li, Z. Wang, F. Ye, L. Huang, The effect of velvet antler proteins on cardiac microvascular endothelial cells challenged with ischemia-hypoxia, Front. Pharmacol. 8 (2017) 1-12. doi:10.3389/fphar.2017.00601.

[63] J.A. García-Vilas, A. Pino-Ángeles, B. Martínez-Poveda, A.R. Quesada, M.Á. Medina, The noni anthraquinone damnacanthal is a multi-kinase inhibitor with potent antiangiogenic effects, Cancer Lett. 385 (2017) 1-11. doi:10.1016/j.canlet.2016.10.037.

[64] N. Kong, K. Lin, H. Li, J. Chang, Synergy effects of copper and silicon ions on stimulation of vascularization by copper-doped calcium silicate, J. Mater. Chem. B. 2 (2014) 1100-1110. doi:10.1039/c3tb21529f.

[65] P. Craig, C. Wood, G.B. McClelland, Oxidative stress response and gene expression with acute copper exposure in zebrafish (Danio rerio)., Am. J. Physiol. Regul. Integr. Comp. Physiol. 293 (2007) 1882-1892. doi:10.1152/ajpregu.00383.2007. 
[66] M. Goldberg, A. Njeh, E. Uzunoglu, Is pulp inflammation a prerequisite for pulp healing and regeneration?, Mediators Inflamm. 2015 (2015). doi:10.1155/2015/347649.

[67] M. V. Thomas, D.A. Puleo, Infection, inflammation, and bone regeneration: a paradoxical relationship, J. Dent. Res. 90 (2011) 1052-1061. doi:10.1177/0022034510393967.

[68] D. Garcia-Olmo, H. Guadalajara-Labajo, Stem cell application in fistula disease, Anal Fistula, 2014: pp. 129-138.

\section{Figure captions}

Figure 1. Schematic diagram of embryos culture exposure and microinjection in vivo assays.

Figure 2. Characterization of MBG and MBG-5Cu materials: (a) Particle size distributions; (b) SAXRD patterns, inset WAXRD patterns; (c) $\mathrm{N}_{2}$ adsorption-desorption isotherms; (d) BJH pore size distribution obtained by the adsorption branch of the isotherm; (e) FT-IR and (f) Raman analyses.

Figure 3. TEM analysis of the studied materials: (a) Micrograph of MBG (Cu free); (b) EDX analysis of area shown in image a; (c) Micrograph of MBG-5Cu showing dark features of 10-50 nm size, decorating the mesostructured substrate, and SAED pattern (inset); (d) EDX analysis of the area shown in image c; (e) Micrograph of MBG-5Cu showing a big crystal (white arrow) and SAED pattern (inset); EDX analysis of the area shown in image e. EDX signals corresponding to $\mathrm{Ni}$ are caused by the use of nickel supporting grids.

Figure 4. Cumulative cell growth curve expressed as total cell count of the experimental groups in the presence of $\mathrm{MBG}$ and $\mathrm{MBG}-5 \mathrm{Cu}$ extracts in comparison with the bare medium control group. The graph displays results of direct cell counting over a 7-day period. The plots represent triplicate measurements for three experiments as mean $\pm \mathrm{SD}\left({ }^{*} p<0.05\right.$; ** $p<0.01$ by Student's t test). 
Figure 5. In vitro BAEC cells migration assay. Cell wound filling of the cleared area, as demarcated by horizontal red lines, was followed at different culture times by an optical microscope. Histogram showing relative wound width at 0,4 and $7 \mathrm{~h}$ of the cell migration experiment. The percentage of area, cell free, is displayed as mean \pm SD from three independent experiments $\left({ }^{*} p<0.05 ; * * p<0.01\right.$ by Student's test).

Figure 6. Representative images of yolk sac SIVs after 5 days exposure for (a) bare medium control and (b) $300 \mathrm{mg} \mathrm{L}^{-1}$ MBG-5Cu groups. White arrows indicate vessels number counted.

Figure 7. SIVs thickness size distributions of $\mathrm{MBG}$ and $\mathrm{MBG}-5 \mathrm{Cu}$ material dispersions and control groups after 5 days exposure assay.

Figure 8. (a) Representative image showing the characteristic "angiogenic" SIVP phenotype. (b) Percentage of zebrafish specimens showing this phenotype after 5 days exposure assay. Statistically significant differences marked as $* p<0.05$ and $* * p<0.01$.

Figure 9. SIVs thickness size distributions of $\mathrm{MBG}$ and $\mathrm{MBG}-5 \mathrm{Cu}$ material dispersions and control groups after 5 days microinjection assay. 
Table 1. Theoretical and measured composition of material particles as determined by XRF quantitative analysis.

$\mathrm{SiO}_{2}: \mathrm{CaO}: \mathrm{P}_{2} \mathrm{O}_{5}: \mathrm{CuO}$ (molar ratio)

Material

Theoretical

Measured

MBG

$80.0: 15.0: 5.0: 0.0$

$86.3: 12.5: 1.2: 0.0$

$\mathrm{MBG}-5 \mathrm{Cu}$

$80.0: 10.0: 5.0: 5.0$

$79.5: 13.2: 0.9: 6.4$ 
Table 2. Textural parameters obtained by $\mathrm{N}_{2}$ physisorption.

\begin{tabular}{lccc}
\hline Material & $\begin{array}{c}\mathrm{S}_{\mathrm{BET}}{ }^{a} \\
\left(\mathrm{~m}^{2} \mathrm{~g}^{-1}\right)\end{array}$ & $\begin{array}{c}\mathrm{V}_{\mathrm{T}}^{b} \\
\left(\mathrm{~cm}^{3} \mathrm{~g}^{-1}\right)\end{array}$ & $\begin{array}{c}\text { Pore size } \\
(\mathrm{nm})\end{array}$ \\
\hline MBG & 353 & 0.33 & 4.3 \\
MBG-5Cu & 239 & 0.24 & 3.7 \\
\hline
\end{tabular}

${ }^{a}$ Specific surface area calculated by the BET method.

${ }^{b}$ Total pore volume estimated from de nitrogen amount absorbed at 0.99 relative pressure.

${ }^{c}$ Pore size distribution was determined by the Barret-Joyner-Halenda (BJH) method using the isotherm adsorption branch. 
Table 3. Ionic product concentration delivery to the media for the material particles measured by ICP-AES during the 5 days-exposure in vivo experiment.

\begin{tabular}{lcccccc}
\hline Material & $\begin{array}{c}\text { Material initial } \\
\text { concentration } \\
\left(\mathrm{mg} \mathrm{L}^{-1}\right)\end{array}$ & $\begin{array}{c}\mathrm{Si} \\
\left(\mathrm{mg} \mathrm{L}^{-1}\right)\end{array}$ & $\begin{array}{c}\mathrm{Cu} \\
\left(\mathrm{mg} \mathrm{L}^{-1}\right)\end{array}$ & $\begin{array}{c}\mathrm{Ca} \\
\left(\mathrm{mg} \mathrm{L}^{-1}\right)\end{array}$ & $\begin{array}{c}\mathrm{P} \\
\left(\mathrm{mg} \mathrm{L}^{-1}\right)\end{array}$ & $\begin{array}{c}\text { \% Material } \\
\text { degradation }^{a}\end{array}$ \\
\hline $\mathrm{CuCl}_{2} 2 \mathrm{H}_{2} \mathrm{O}$ & 0.05 & -- & 0.015 & -- & -- & --- \\
$\mathrm{MBG}$ & 300 & 4.300 & -- & 3.100 & 0.009 & 4.04 \\
& 3000 & 37.400 & -- & 15.500 & 0.100 & 3.53 \\
$\mathrm{MBG}-5 \mathrm{Cu}$ & 300 & 5.000 & 0.005 & 3.300 & 0.017 & 4.79 \\
& 3000 & 36.300 & 0.171 & 20.700 & 0.128 & 3.49 \\
\hline
\end{tabular}

${ }^{a}$ Degradation was calculated from the dissolved silica and the experimental material composition as measured by XRF. 
Table 4. Number and thickness of SIVs measured after 5 days-exposure to the studied material dispersions and control groups. The Table includes the statistical significance of the experimental groups measured with respect to the bare medium control group (codes: $* p<0.05$; $*^{*} p<0.01 ; * * * p<0.001$ ). Additional comparisons in pairs between all groups are displayed in Figs. S1 and S2.

\begin{tabular}{lccc}
\hline & $\begin{array}{c}\text { Concentration } \\
\left(\mathrm{mg} \mathrm{L}^{-1}\right)\end{array}$ & $\begin{array}{c}\text { SIVs } \\
\text { Number }\end{array}$ & $\begin{array}{c}\text { SIVs } \\
\text { Thickness }(\mu \mathrm{m})\end{array}$ \\
\hline Bare medium & -- & $6.2 \pm 1.5$ & $6.03 \pm 1.59$ \\
$\mathrm{CuCl}_{2} 2 \mathrm{H}_{2} \mathrm{O}$ & 0.05 & $7.3 \pm 3.3$ & $6.04 \pm 1.52$ \\
$\mathrm{MBG}$ & 300 & $8.1 \pm 2.7^{*}$ & $6.70 \pm 1.70^{* *}$ \\
& 3000 & $8.6 \pm 2.5^{* *}$ & $6.82 \pm 1.80^{* *}$ \\
$\mathrm{MBG}-5 \mathrm{Cu}$ & 300 & $10.6 \pm 3.5^{* * *}$ & $7.58 \pm 2.31^{* * *}$ \\
& 3000 & $6.8 \pm 2.9$ & $7.44 \pm 1.89^{* * *}$ \\
\hline
\end{tabular}


Table 5. Number and thickness of the SIVs measured after 5 days-microinjection of material dispersions and control groups. The Table includes the statistical significance of the experimental groups measured with respect to the bare medium control group (codes: ${ }^{*} p<0.05$; $\left.*^{*} p<0.01\right)$. Additional comparisons in pairs between all groups are displayed in Figs. S3 and S4.

\begin{tabular}{lccc}
\hline & $\begin{array}{c}\text { Concentration } \\
\left(\mathrm{mg} \mathrm{L}^{-1}\right)\end{array}$ & $\begin{array}{c}\text { SIVs } \\
\text { Number }\end{array}$ & $\begin{array}{c}\text { SIVs } \\
\text { Thickness }(\mu \mathrm{m})\end{array}$ \\
\hline Bare medium & -- & $6.0 \pm 1.5$ & $5.57 \pm 1.19$ \\
$\mathrm{CuCl}_{2} 2 \mathrm{H}_{2} \mathrm{O}$ & 0.05 & $6.1 \pm 2.0$ & $5.69 \pm 1.20$ \\
$\mathrm{MBG}$ & 300 & $6.3 \pm 2.5$ & $5.98 \pm 1.39^{*}$ \\
& 3000 & $6.1 \pm 2.2$ & $5.10 \pm 0.87$ \\
$\mathrm{MBG}-5 \mathrm{Cu}$ & 300 & $6.8 \pm 2.0$ & $6.16 \pm 1.37 * *$ \\
& 3000 & $6.5 \pm 1.5$ & $5.62 \pm 1.51$ \\
\hline
\end{tabular}


Table 6. Percentage of zebrafish specimens showing moderate kyphosis after 5 daysmicroinjection of material dispersions and control groups. The Table includes the statistical significance measured with respect to the bare medium control group (codes: $* p<0.05 ; * * * p<0.001$ ). Additional comparison in pairs between all groups is displayed in Fig. S5.

\begin{tabular}{lcc}
\hline & $\begin{array}{c}\text { Concentration } \\
\left(\mathrm{mg} \mathrm{L}^{-1}\right)\end{array}$ & $\begin{array}{c}\text { Zebrafish with } \\
\text { malformations (\%) }\end{array}$ \\
\hline Bare medium & -- & 0 \\
$\mathrm{CuCl}_{2} 2 \mathrm{H}_{2} \mathrm{O}$ & 0.05 & 0 \\
$\mathrm{MBG}$ & 300 & 0 \\
& 3000 & $13^{*}$ \\
$\mathrm{MBG}-5 \mathrm{Cu}$ & 300 & 0 \\
& 3000 & $67^{* * *}$ \\
\hline
\end{tabular}




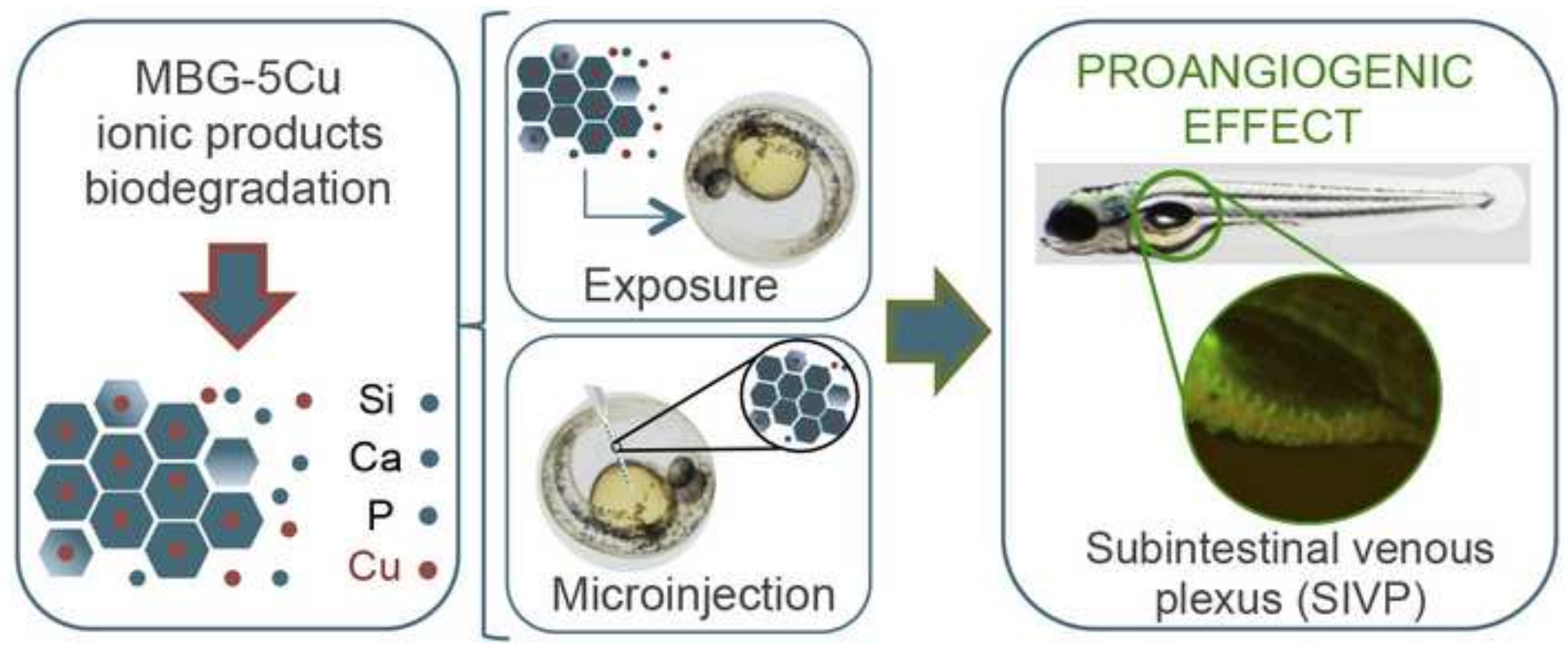




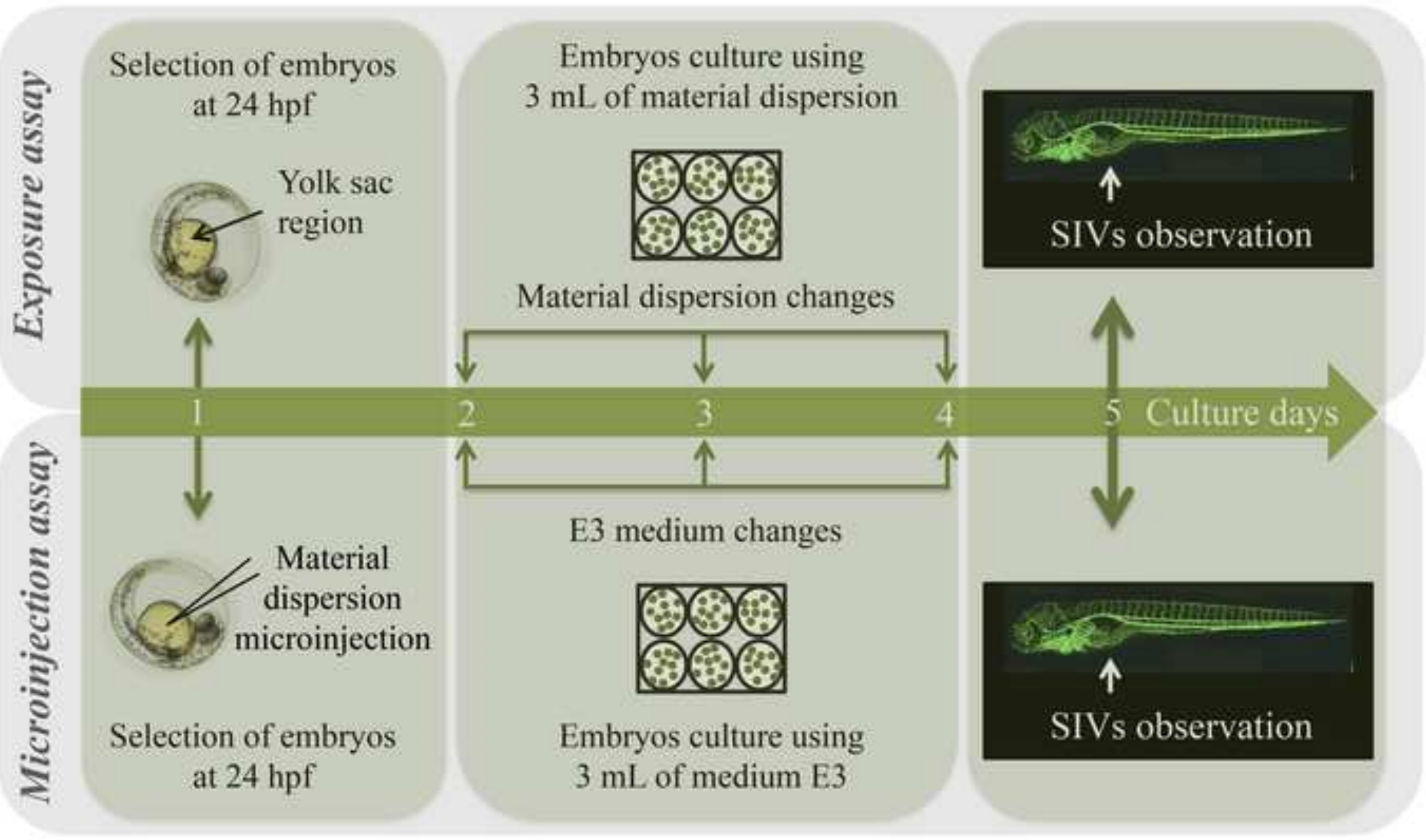


a

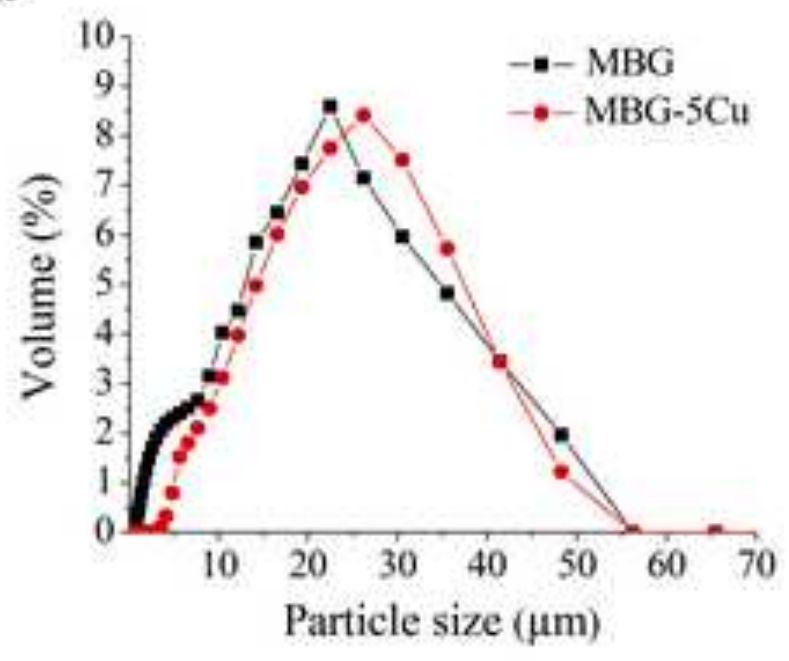

C

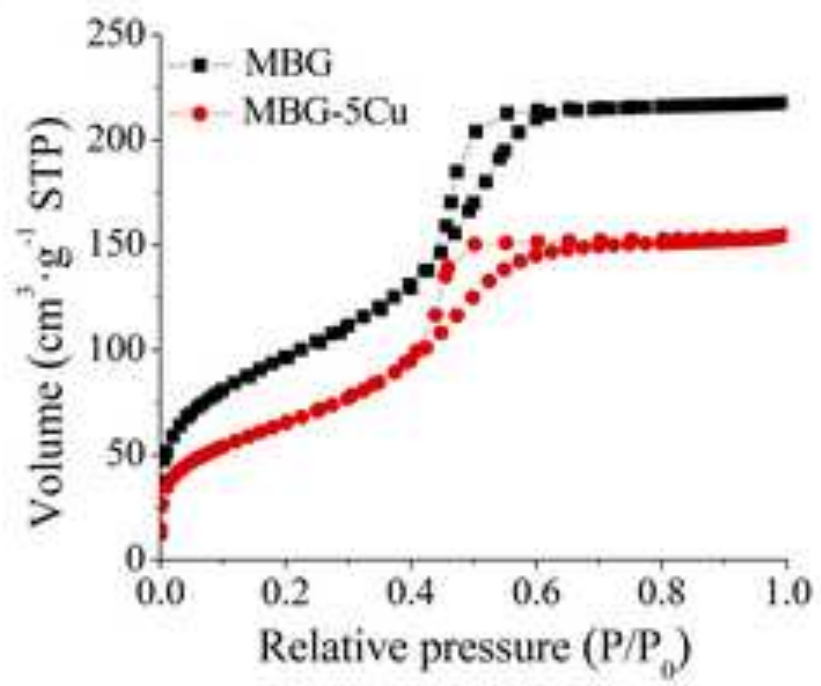

e

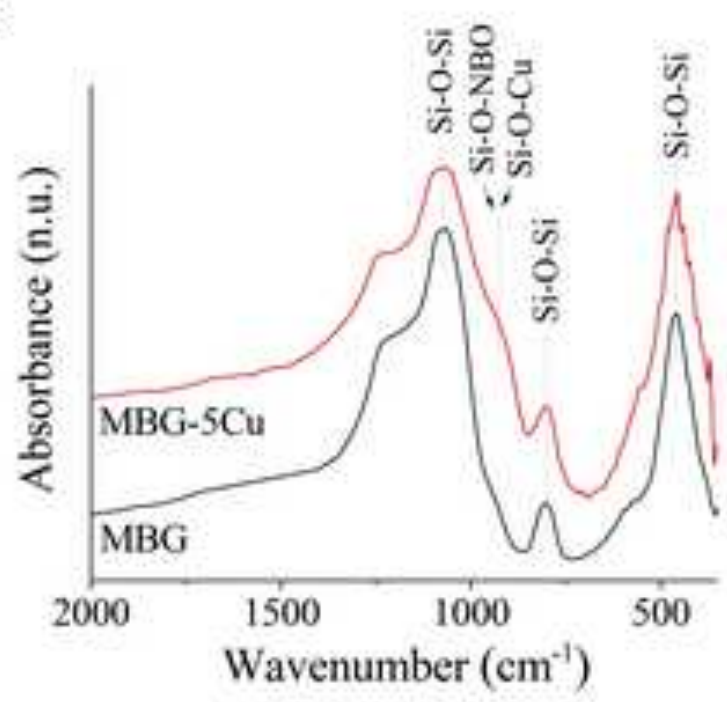

b

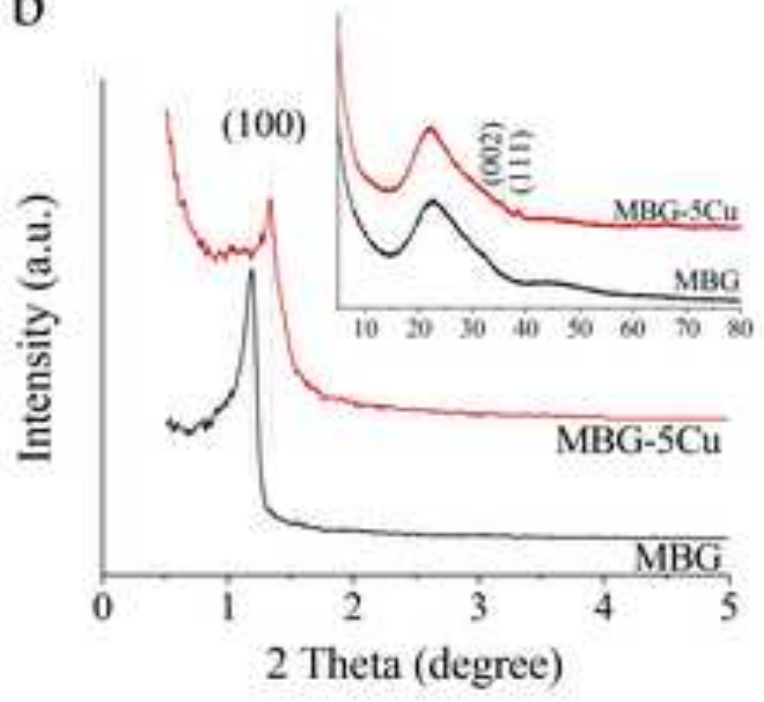

d

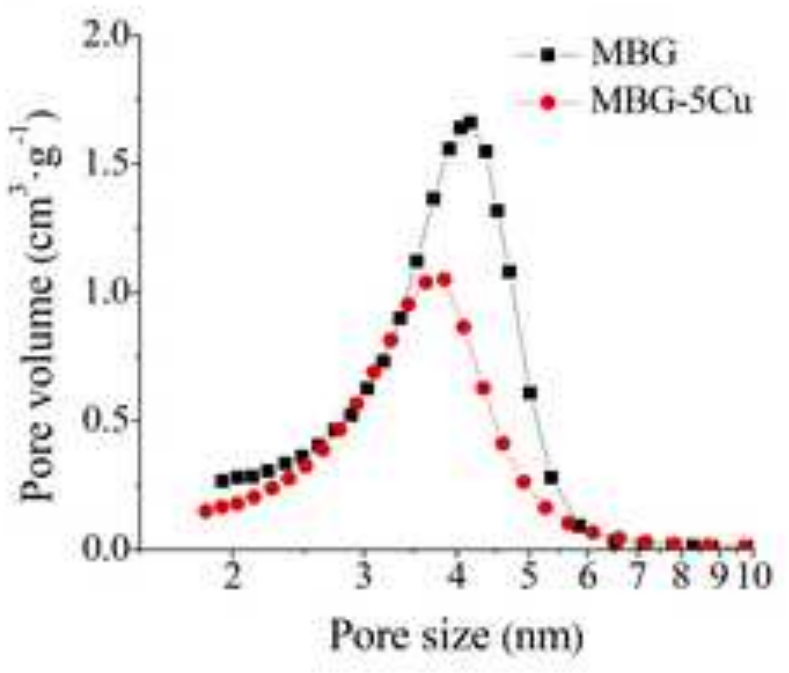

f

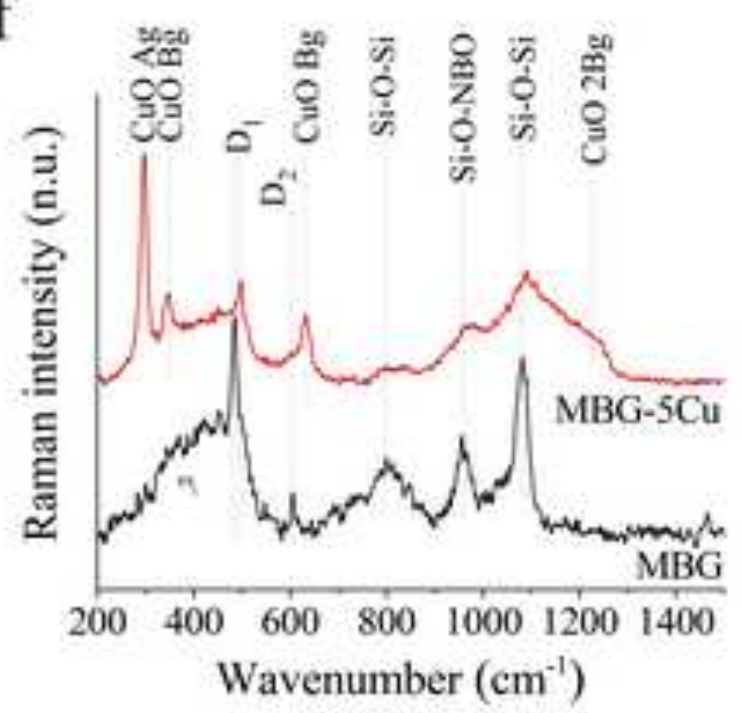


Figure 3

Click here to download high resolution image

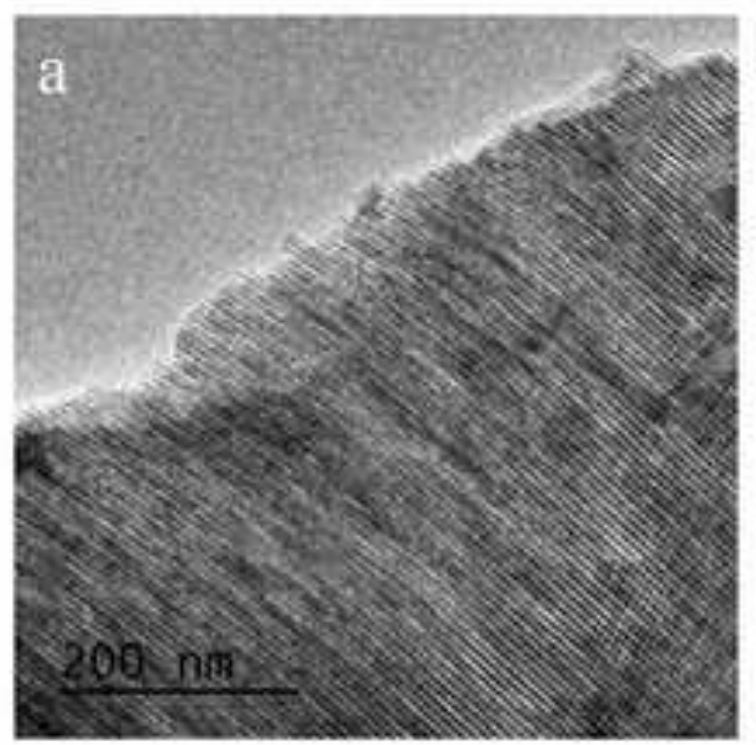

b
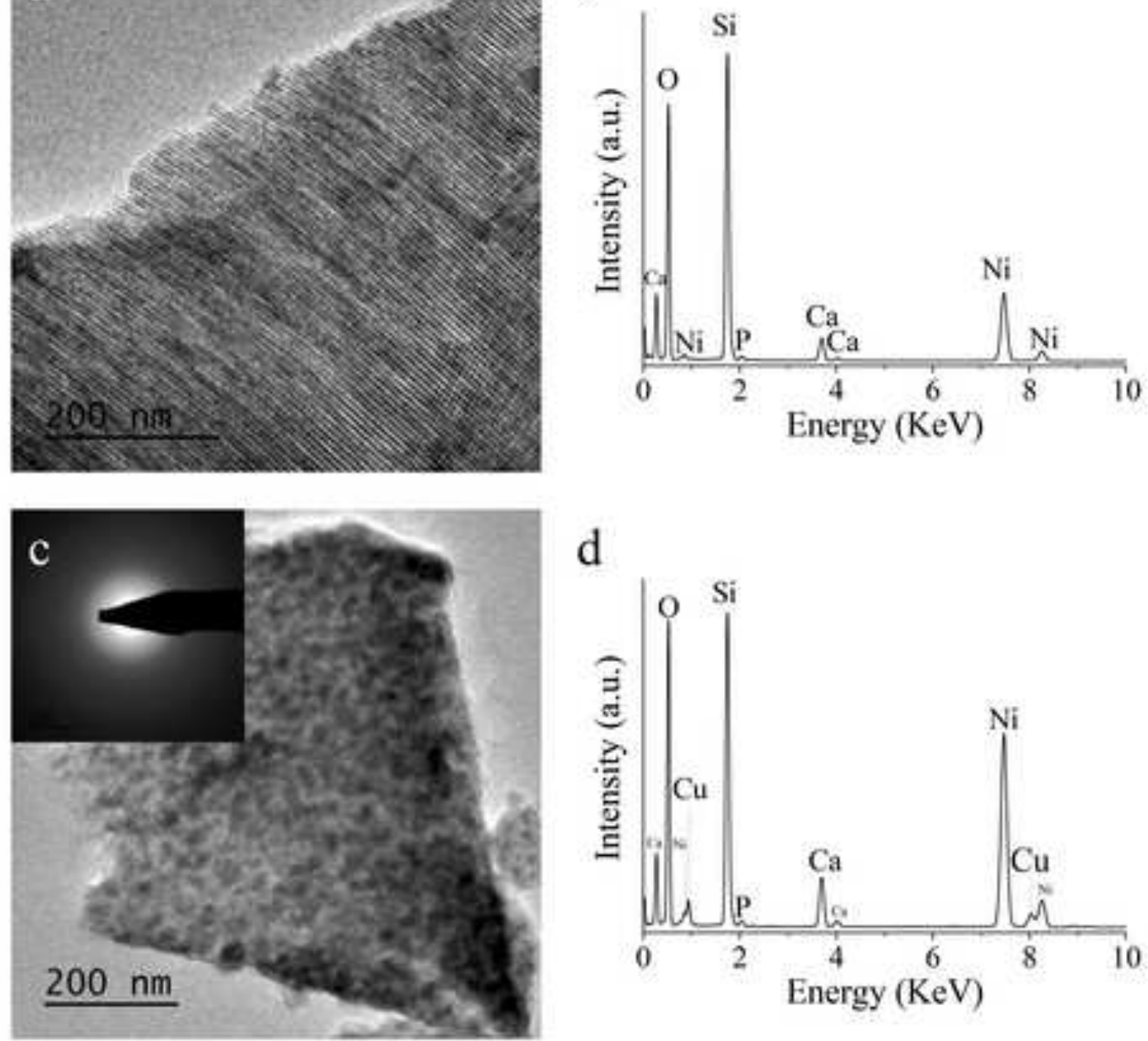

d
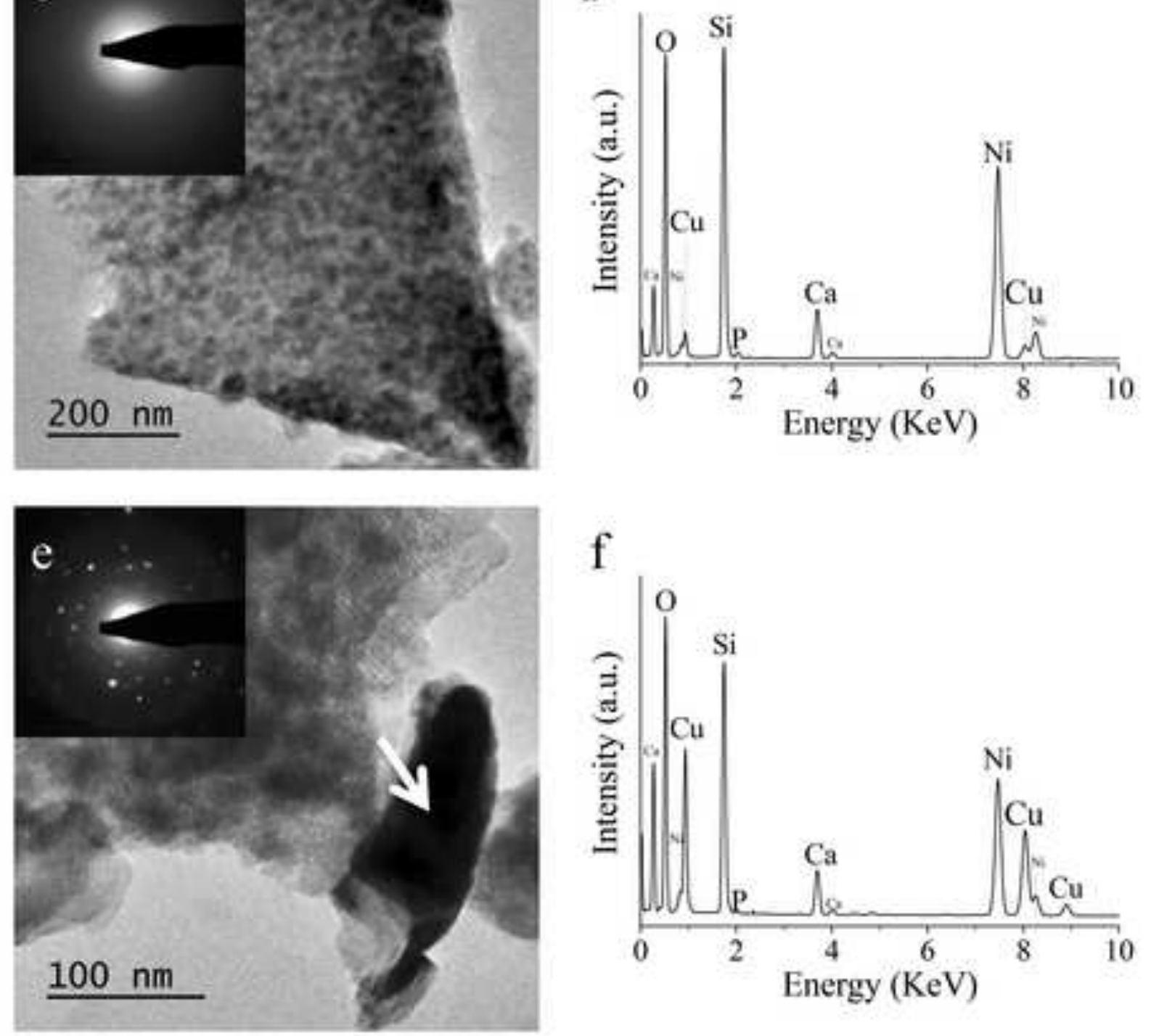


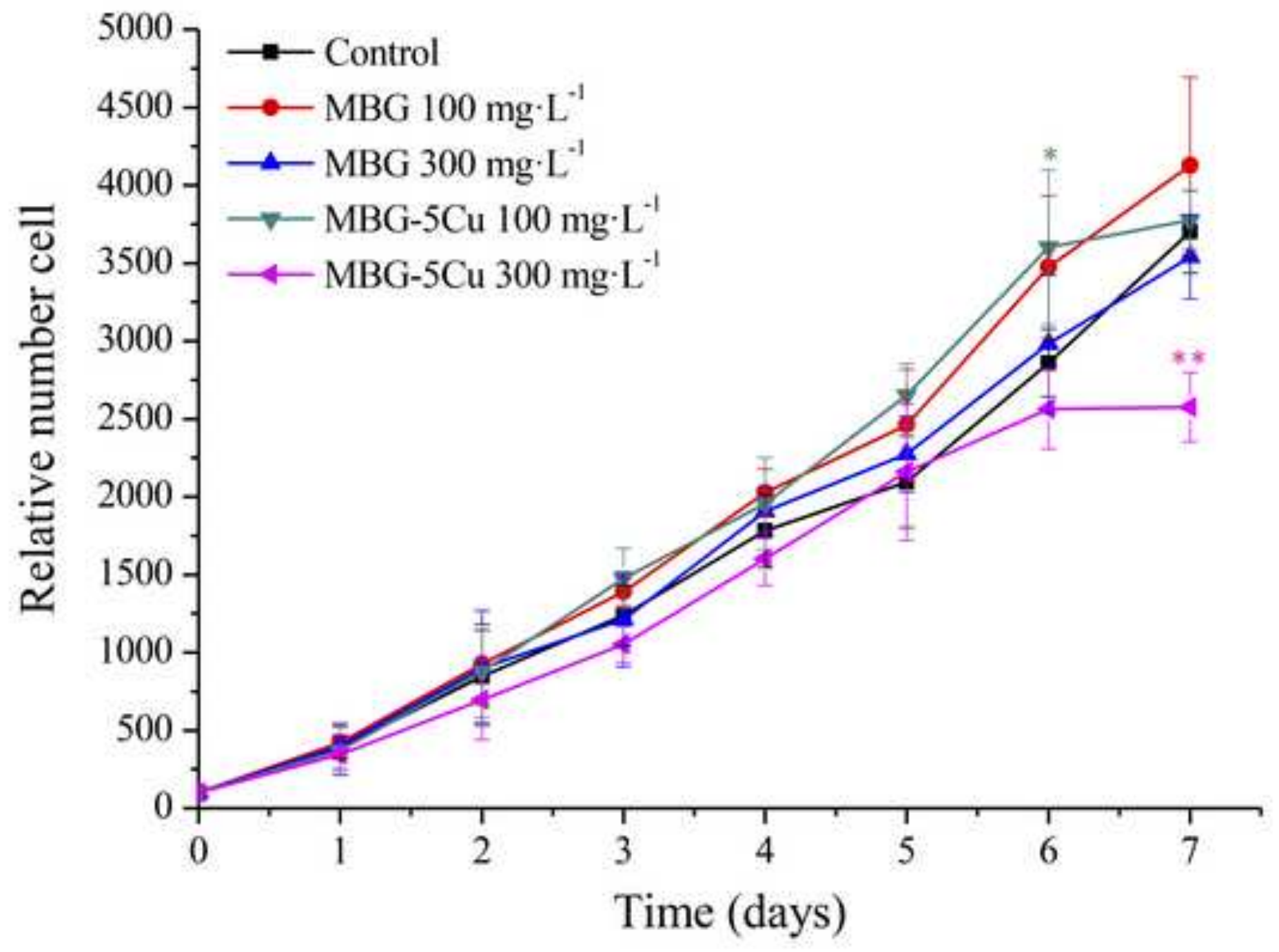



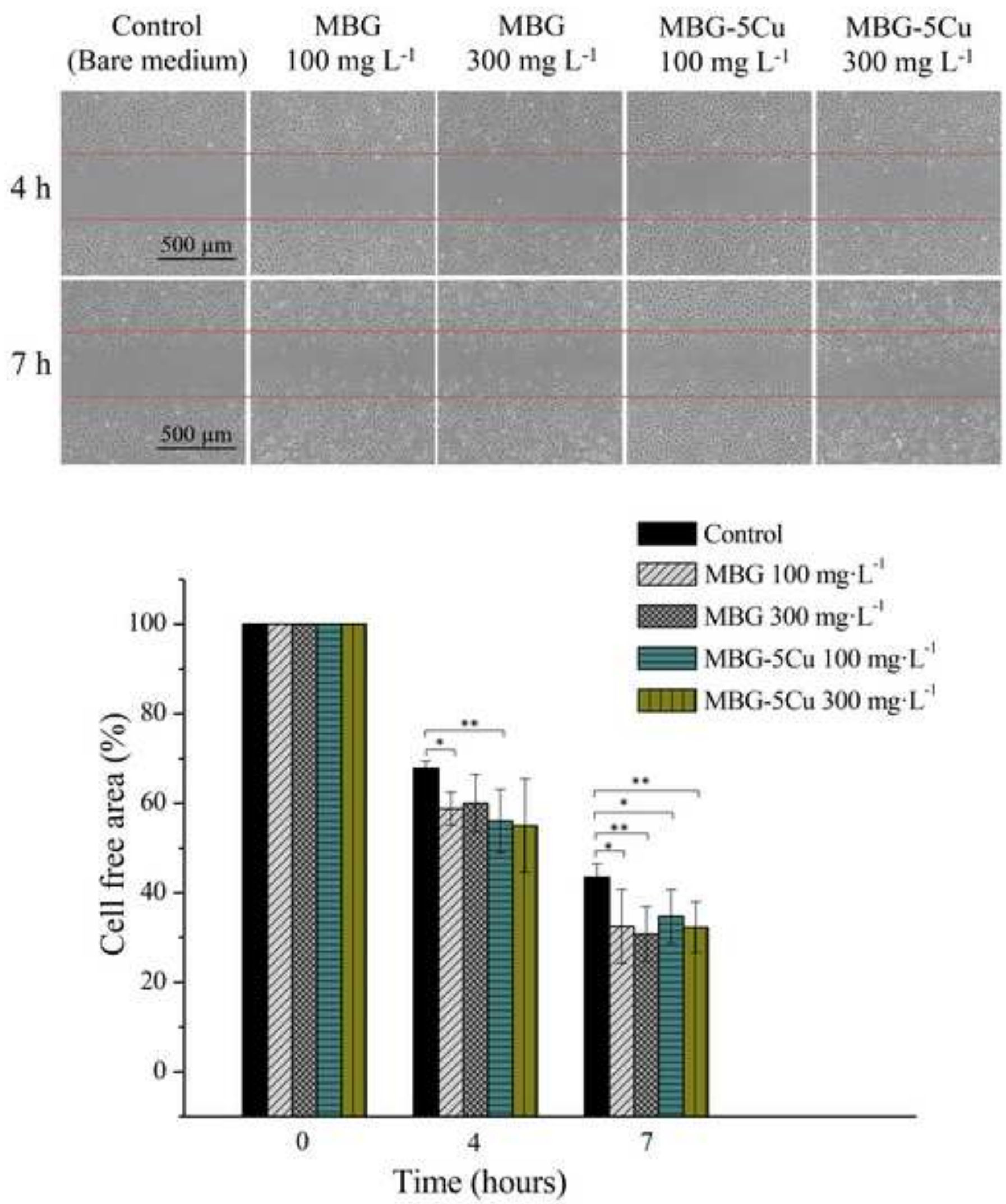

Control

एIA MBG $100 \mathrm{mg} \cdot \mathrm{L}^{-1}$

MBG $300 \mathrm{mg} \cdot \mathrm{L}^{-1}$

MBG-5Cu $100 \mathrm{mg} \cdot \mathrm{L}^{-1}$

III MBG-5Cu $300 \mathrm{mg} \cdot \mathrm{L}^{-1}$

4

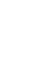


Click here to download high resolution image
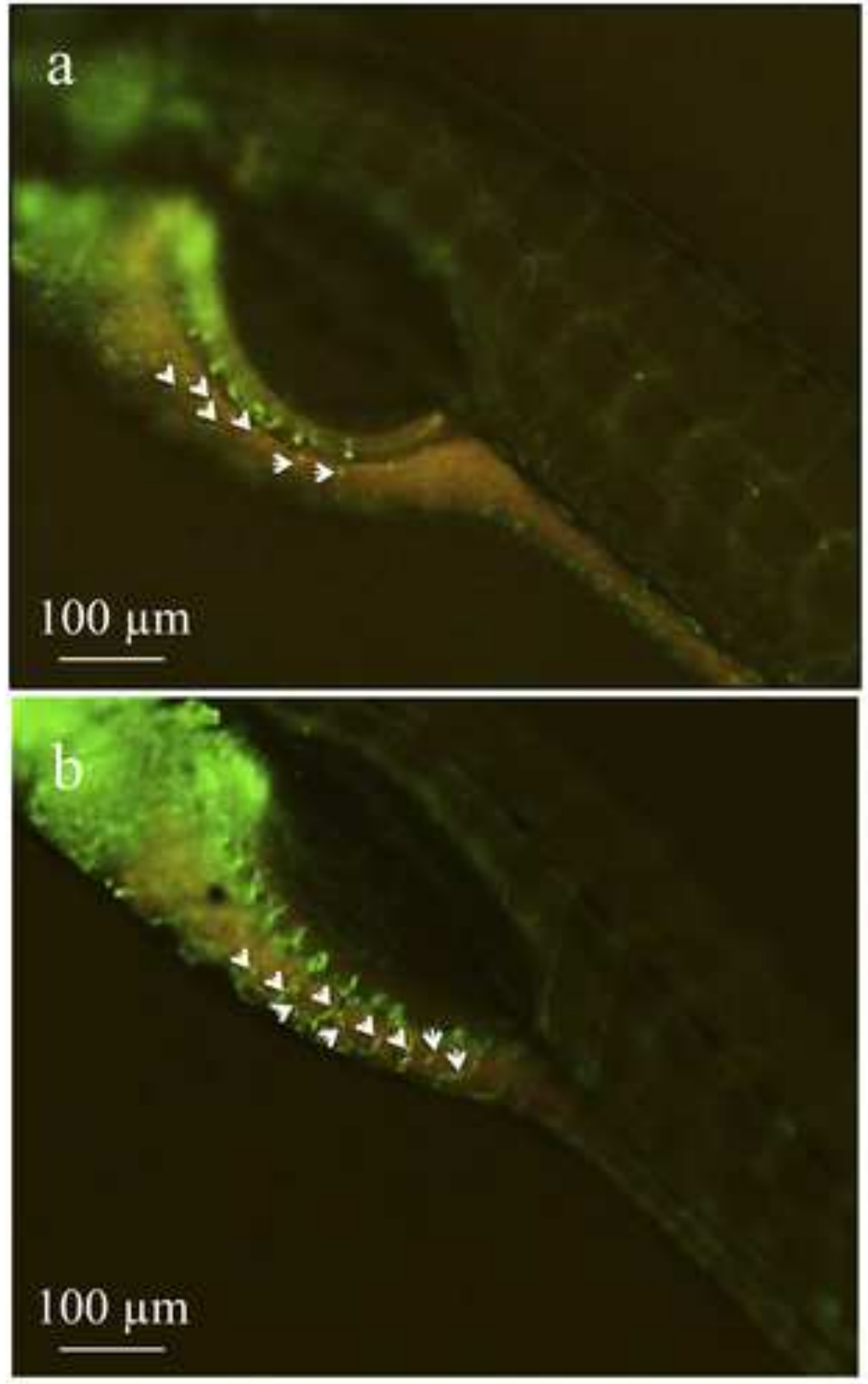


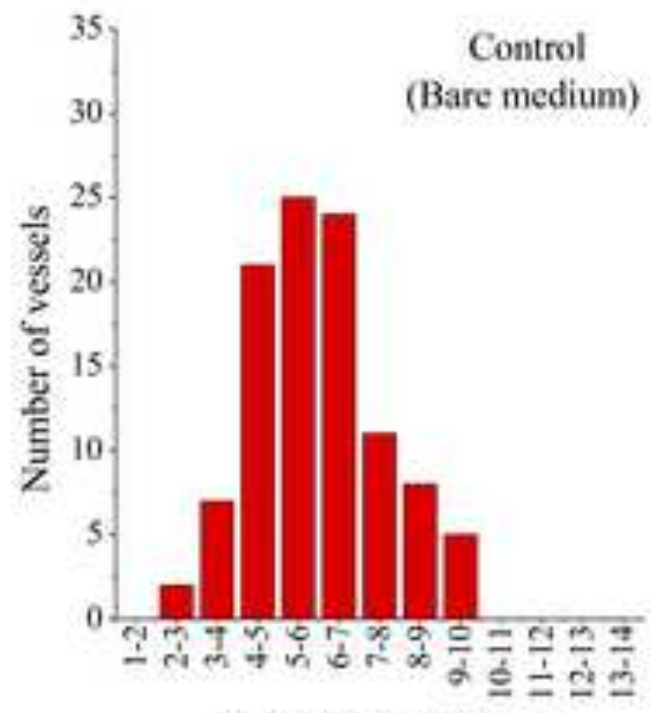

Vessel thickness ( $\mu \mathrm{m})$

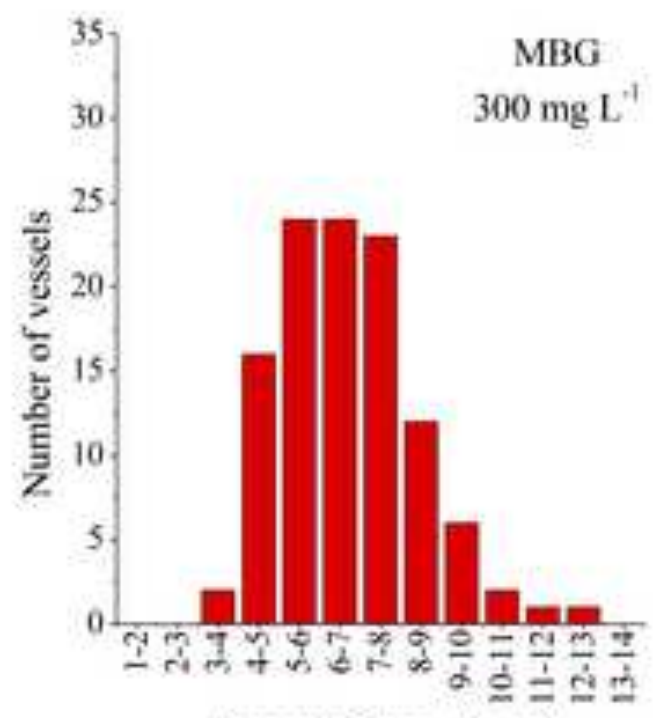

Vessel thickness ( $\mu \mathrm{m})$

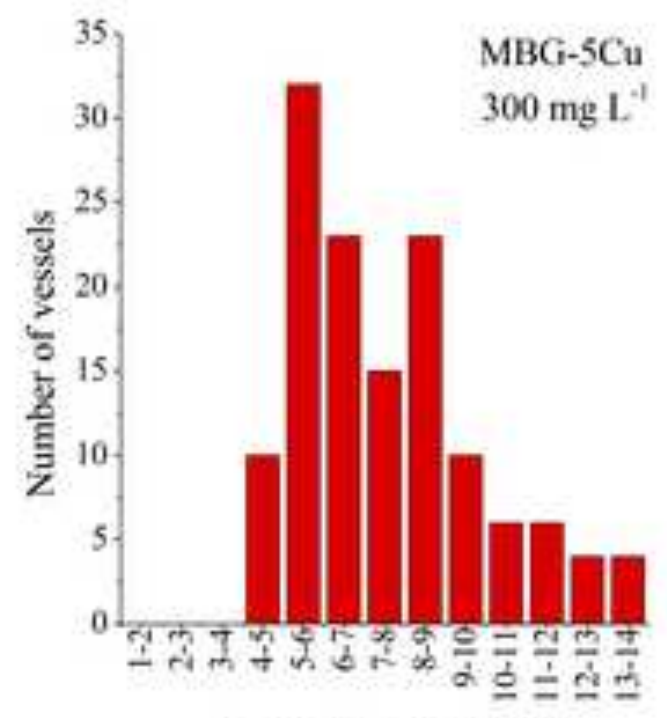

Vessel thickness ( $\mu \mathrm{m})$
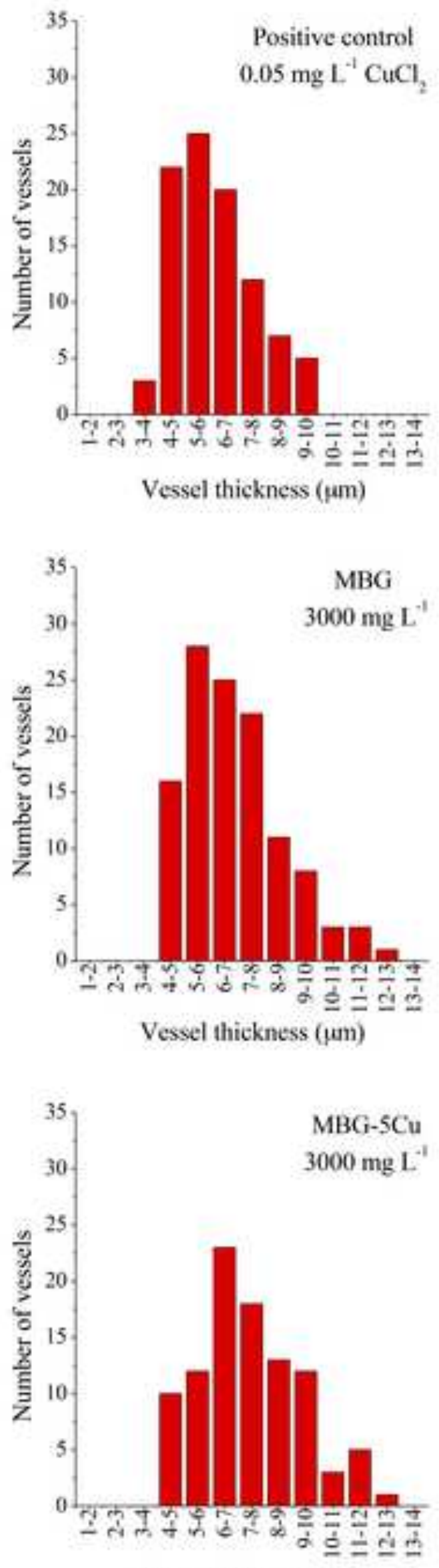

Vessel thickness ( $\mu \mathrm{m})$ 
Figure 8
Click here to download high resolution image

a

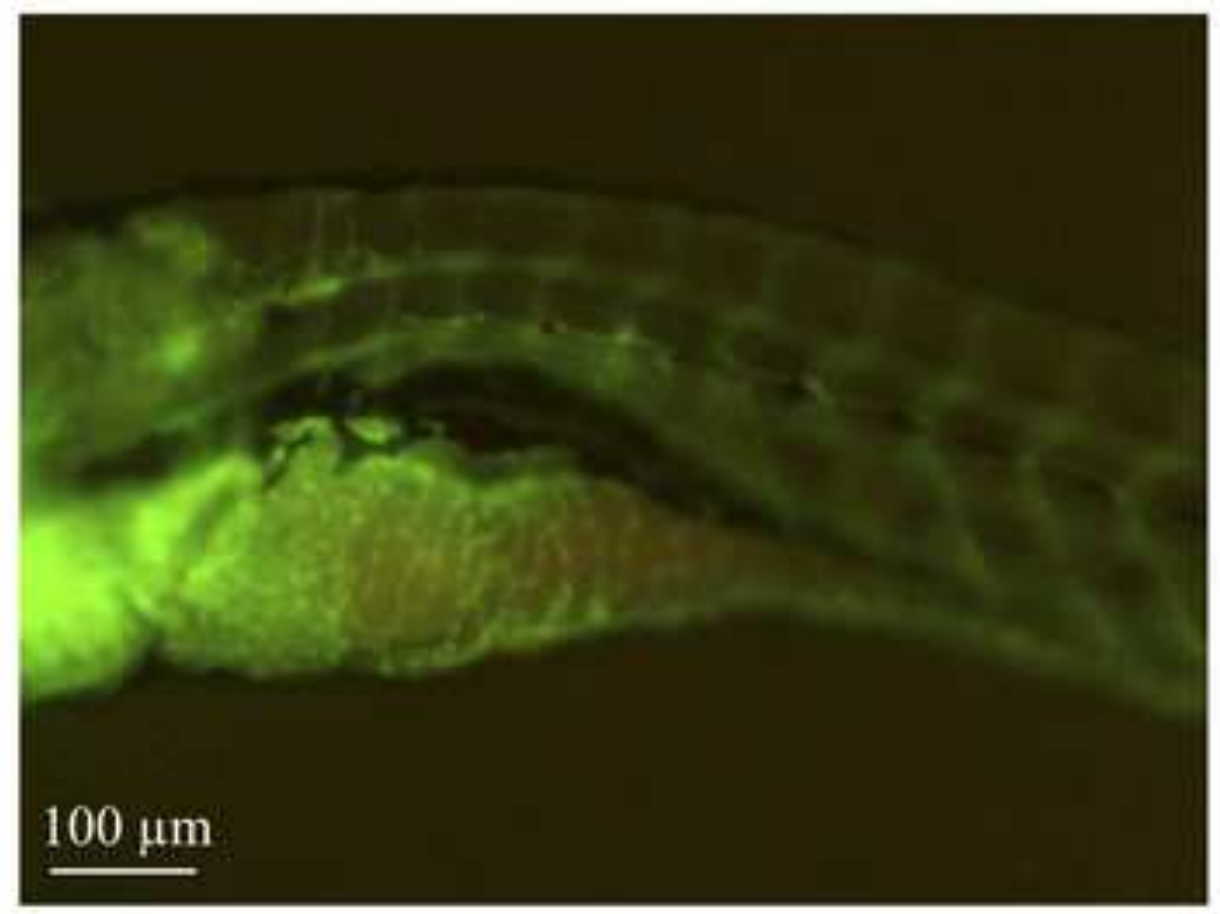

b

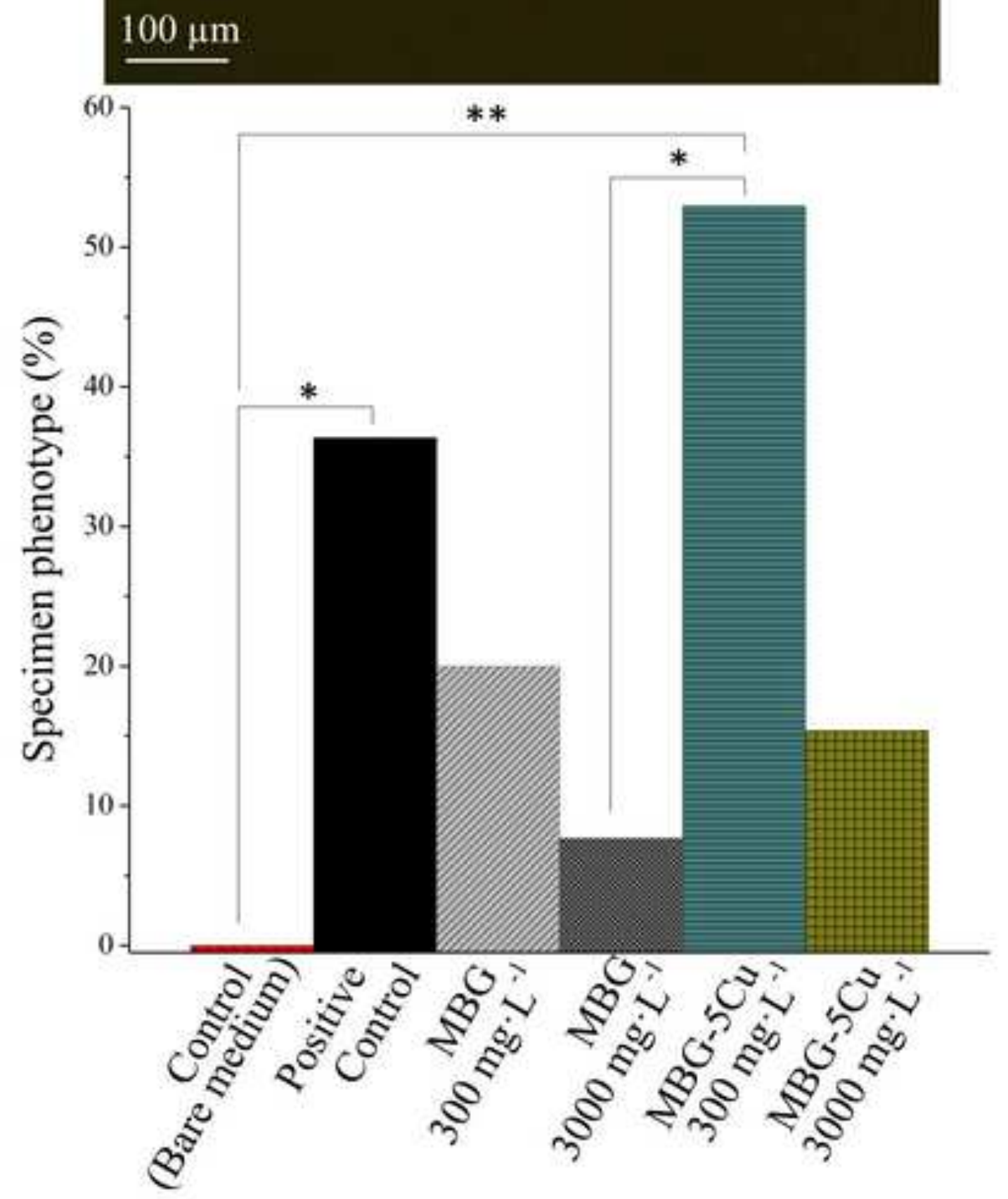




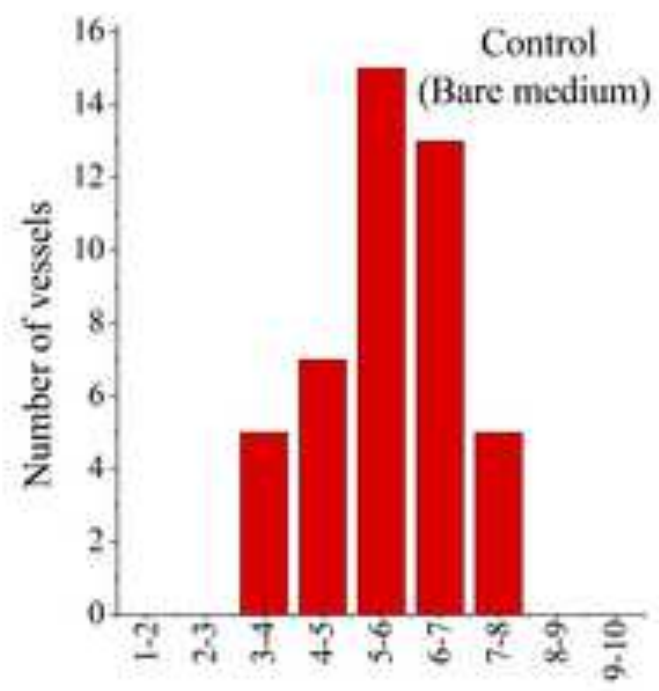

Vessel thickness ( $\mu \mathrm{m})$

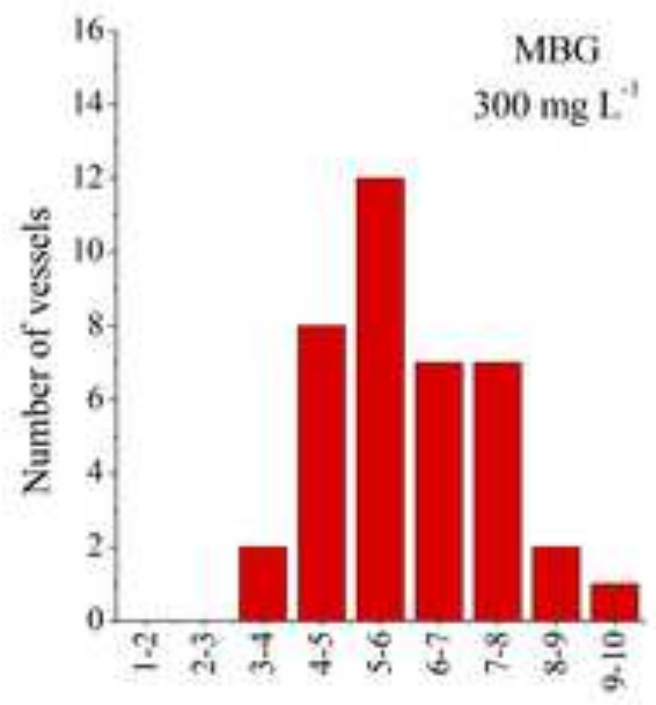

Vessel thickness ( $\mu \mathrm{m})$

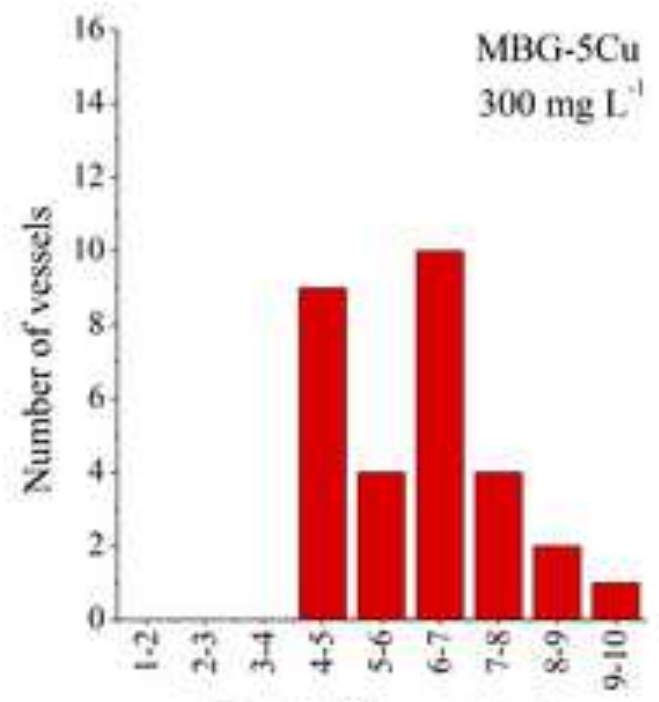

Vessel thickness ( $\mu \mathrm{m})$

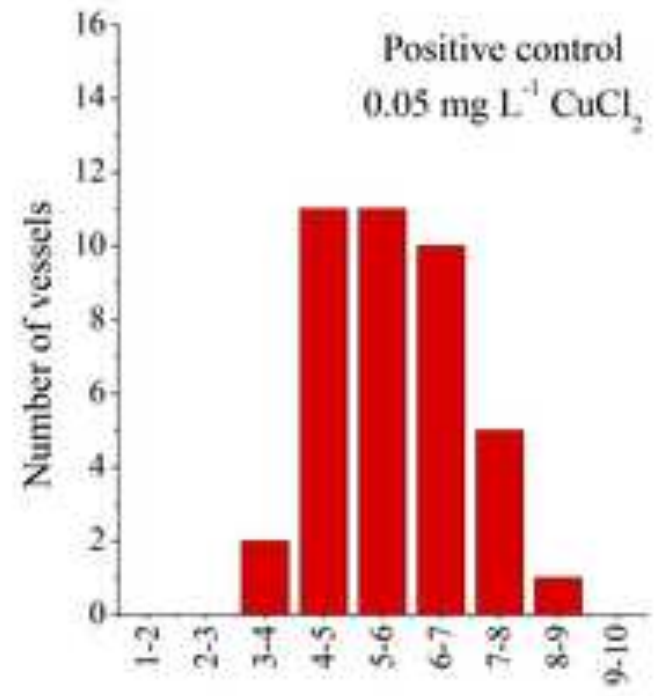

Vessel thickness $(\mu \mathrm{m})$
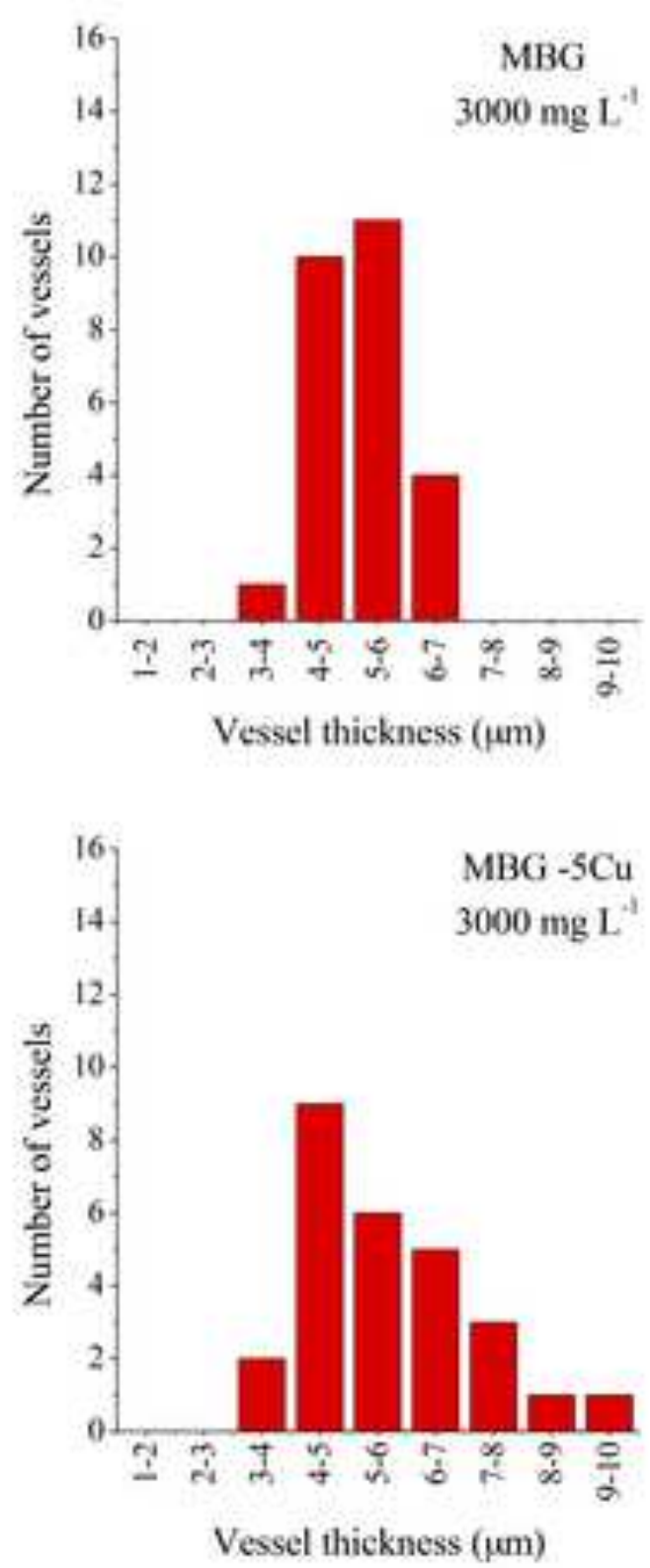
Supplementary Material
Click here to download Supplementary Material: Supplnf_LBRS_AB_17-1735.docx

Clik here to download Supplementary Material: Supplnf_LBRS_AB_17-1735.docx

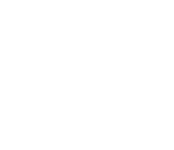

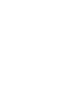

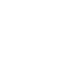

.

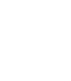

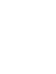

(1)

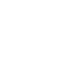

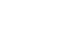

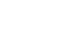

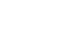

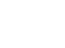

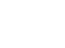

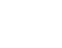

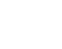

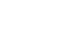

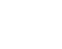

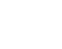

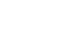

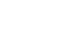

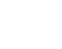

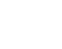

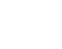

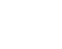

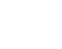

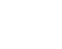

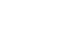

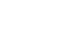

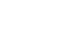

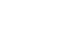

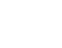

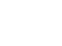

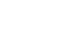

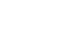

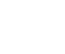

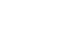

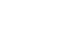

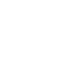

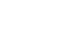

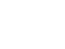

